\title{
¿Dónde se escribió la carta a los Filipenses?
}

Fuera de contadas excepciones hasta el s. XIX se ha venido proponiendo Roma como lugar de origen y la cautividad romana (Hch 28,16.30s) como período en el cual datar la composición de la Carta a los Filipenses ${ }^{1}$. Perduró así una tradición, cuyo primer testigo es un prólogo marcionita del s. II, aceptándose sin discusión luego por parte de los comentaristas de los ss. IVv. Quienes rechazan el origen romano, creen que en este caso no estamos ante una tradición auténtica, sino ante deducciones hechas a base del NT y ante la persuasión de que Pablo tenía que mostrarse cada vez más perfecto en sus Cartas. Como argumento corroborante se cita a Orígenes, que coloca a Filipenses antes de 1 Corintios (PG XIV 834 B-C).

Los primeros en discordar de la tradición común fueron G. L. Oeder ${ }^{2}$, que propuso Corinto como lugar de origen (a. 1731); H.E.G. Paulus ${ }^{3}$ (a. 1799) y D. Schulz ${ }^{4}$ (a. 1829) que se declararon a favor de Cesarea; al comenzar el presente siglo (a. 1900) H. Lisco ${ }^{5}$ ubicó en Éfeso la composición, tesis que gozó de una gran aceptación entre los investigadores de este siglo. Ha sido en el s. XX cuando Éfeso, Cesarea y Corinto han disputado verdaderamente a Roma al ser el lugar donde Filipenses se redactó.

De la "Carta" misma se deducen con seguridad relativamente muy pocas cosas para determinar con precisión el lugar de composición de este escrito:

-Pablo se encuentro preso (1,7.13.14.17; 2,23; cf. 2,17; 4,14).

1. Fuera de los comentarios, que al principio suelen tratar el tema de modo más o o menos extenso puede consultarse la bibliografía al final del artículo.

2.. W. Michaelis, Einleitung in das Neuen Testament, Bern $1954^{2}, 204 \mathrm{~s}$.

3. J. SCHMID, Zeit und Ort der paulinischen Gefangenschaftsbriefe, Freiburg 1931, 2, $1^{\circ}$

4. D. ScHulz, ThStkr 2 (1829) 612-617.

5. H. Lisco, Vincula Sanctorum, Berlín 1900. 
-El lugar donde Pablo se encuentra preso se llama "pretorio" $(1,13)$.

-En la población, donde se pone por escrito la "Carta", reside gente "de la casa del César" $(4,22)$.

-Según el propio autor, la razón, por la que se encuentra preso, es la predicación del Evangelio (1,13).

-El final de la prisión aparece como probable en breve tiempo $(1,26$; 2,24).

Los Hechos de los Apóstoles testifican que Pablo estuvo preso en varias ocasiones, aunque probablemente hubo más encarcelamientos. Ellos dan cuenta de:

-Una brevísima prisión en Filipos (Hch 16.23-39).

-La prisión en Jerusalén (Hch 21, 23-23, 39), relativamente breve también.

-Una prisión en Cesarea (Hch 23, 24-26, 32) de una duración de unos dos años.

-Un viaje de Cesarea a Roma en condición de preso (Hch 27, 1-28, 15).

-Una prisión en Roma de al menos 18 meses (Hch 28,30).

En 2 Cor 11,23 atestigua el propio Pablo haber estado preso en varias ocasiones y en 2 Cor 1, 8-10 haberse encontrado en la provincia de Asia en una situación tan desesperada, que llegó a contar con la muerte.

De estos pocos datos no cabe establecer conclusiones absolutas a favor de una u otra de las ciudades que se disputan el honor de ser el lugar de origen de este escrito; incluso cuando se ha ido excluyendo una tras otra hasta quedarse con una sola, siempre queda la duda en el ánimo, pues alguno de los datos parecerá favorecer a una u otra de las excluidas frente a la que parece explicar mejor la situación. Presentaremos por ello primero los argumentos que parecen afectar a todas y luego los que favorecen los derechos de cada una en particular.

\section{A. La prisión}

Pablo según Fp 1, 7.13.14.17; 2,23: cf. 2, 17; 4, 14 se encuentra en la cárcel cuando escribe la Carta a los Filipenses. La impugnación de este dato por T. W. Manson ${ }^{6}$, afirmando que Fp 1, 12-18 se refiere a sucesos de su primera estancia en Corinto (Hch 18, 12-17) y a los acontecimientos que siguieron (1 Cor 1-4) y por tanto se trata de hechos pasados y no presentes cuando se

6. T. W. Manson, St. Paul in Ephesus. The Date of the Epistle to the Philippians, BJRL 23 (1939) 182-200. 
escribe la "Carta" y que el vocablo "cadenas" es una imagen para describir los sufrimientos a que le llevó cotidianamente el anuncio del Evangelio (Cf. 1 Cor 15,31), necesita ser demostrada, pues se encuentra en oposición a las afirmaciones claras del autor de encontrarse en prisión y del sentido obvio de Fp 1, 12-18.

Fp 1,13 especifica que el lugar de prisión de Pablo se encuentra en el "pretorio". De este dato solía concluirse que era indudablemente Roma el lugar donde Pablo se encontraba preso cuando escribió Filipenses. Lohmeyer tuvo el acierto de recordar, que cuando Pablo es conducido a Cesarea, se le confina en el "pretorio de Herodes" (Hch 23, 35).

El vocablo "pretorio" es un término técnico, pero no exclusivo de Roma o Cesarea. Primitivamente designó la tienda del general o el cuartel general en el campo. De ahí derivó el sentido que tiene en el NT: "residencia oficial de un gobernador o de un príncipe" (Mc 15, 16; Mt 27, 27; Jn 18, 28.33; 19,9; Hch 23,35$)$ y como en una de las salas tenían lugar las audiencias judiciales, se empezó a denominar a ésta: "sala del juicio" o "pretorio":

"Los soldados lo llevaron dentro del aula, del pretorio" (Mc 15,16).

Juvenal recordará: "sedet ad praetoria regis" (Sat. X, 161; cf. ActThom 3; Tertuliano, Ad Scap 3). En Roma, más que al palacio imperial, se aplicó a los cuarteles donde residía la guardia imperial, o al grupo de hombres que la formaban (T. Livio, 26, 15; 30, 5; Suetonio, Nerón 9) ${ }^{7}$. El término parece que se aplicó tanto a Roma como al lugar donde residía el gobernador romano de la provincia. J. J. Gunther pretende limitar la denominación de "pretorio" a solos los casos en los que el gobernador ("praefectus") estuviera bajo el control directo del emperador, como era el caso de Palestina. Tal sugerencia, empero, no ha sido aceptada ${ }^{8}$. J. T. Wood ${ }^{9}$ apuntó la posibilidad de la presencia en Éfeso de una cohorte pretoriana.

Según Fp 1,13: "la guardia pretoriana (-pretorio-) y todos los demás han visto claro que si llevo cadenas, por Cristo las llevo”. Esta afirmación a primera vista parece excluir tanto la prisión cesariense como la romana, ya que en ambas Pablo estuvo preso bajo la acusación de violación del reglamento del templo de Jerusalén (Hch 21,$28 ; 24,6 ; 25,8 ; 28,17$ ). Pero hay que tener en cuenta que Pablo interpretó su prisión como un pretexto, por parte de los judíos, para camuflar su hostilidad radical contra el Evangelio y contra su persona y enseñanza (Hch 26,$7 ; 28,18-20)$. Sus persecuciones y sufrimientos

7. B. RIECKE, Cesarea, Rome and the Captivity Letters, en Apostolic History and Gospel, (W. W. Gasque-R. OP. Martin, eds.), Exeter 1970, 277-285.

8. J. J. Gunther, Paul: Messenger and Exile, Valley Forge 1972.

9. J. T. Wood, Discoveries at Ephesus, London 1887, App. 7, n. 2. 
han sido causados por su predicación del Evangelio, anunciando éste a los gentiles (1Tes 2,16; Col 1,24; 2,1; Ef 3,13). La argumentación no es, sin embargo, concluyente, ya que a los ojos de Pablo el primer motivo encubre el segundo, que es la verdadera razón de todo el proceso, siendo éste como un epígono de la persecución, de la que él es objeto de parte de sus antiguos correligionarios.

También la expresión: "todo el pretorio", si se la aplica a la guardia imperial residente en Roma y que abarcaba a unos 9.000 hombres, debe considerarse una exageración; si en cambio se aplicase a un pequeño grupo de tal guardia, destacado en provincias, ya no parecería tan exagerado y se tornaría más comprensible.

La prisión ha llevado a Pablo a una situación de inminente peligro de muerte, según aparece reflejado en Fp 1,20.23.30; 2,17. Esto lo han interpretado algunos como prueba inequívoca de que Pablo debía encontrarse en Roma y después de su apelación al tribunal del César en Cesarea, pues como ciudadano romano, de encontrarse en cualquier otra ciudad, podía escapar a la sentencia de cualquier tribunal provincial, alegando su condición de ciudadano romano y apelando al tribunal de César (Hch 25,10-11). Pero la situación a la que Filipenses apunta, no concuerda con el ambiente final que reflejan los Hechos de los Apóstoles (28,30-31). Habría que suponer un desarrollo desfavorable para Pablo de sus relaciones con las autoridades estatales y judiciales, operándose un cambio de perspectivas y de situación, que habría llevado a un cambio de la "custodia libera" (Hch 28,16.30s; cf. Eusebio, HE 2,22,1) por la de confinamiento escricto con el peligro que Filipenses delata. Pero ningún otro dato confirma este posible cambio. Por eso es mejor intentar otro camino, que explique adecuadamente la situación de Fp $1,20.23,30 ; 2,17$, sin oponerla a la descrita por Hch $28,16.30$ s. Y tal ocurre en concreto en Cesarea...

E. F. Scott ${ }^{10}$ opina que Pablo no corría en Cesarea el peligro que presuponen los textos citados de Filipenses, pues aunque la prisión pudiera ser tediosa y molesta, no parece que la misma pueda justificar el tono martirial de Fp 1,20ss; como a Pablo le queda siempre el recurso al César, parece enteramente extraño ese modo de pensar.

Los temores de Pablo, de escribirse la "Carta" en Cesarea, no parecen tan injustificados como Scott piensa y pudiera aparecer a primera vista. A pesar de la "custodia romana" el peligro no desaparece para él mientas se encuentre en Cesarea; al contrario, aumenta cada día que dicha prisión se prolonga. En esta ciudad siempre hay que contar con el riesgo de una entrega a las autorida-

10. E. F. Scotr, The Epistle to the Philippians, New York 1955,5. 
des locales del preso, lo que conllevaría una muerte segura (Hch 25,3; cf. 23,12-15). Y que tal entrega no fuera cosa extraña lo demuestran:

-El caso de Jesús, que a pesar de las declaraciones de inocencia por parte de la autoridad judicial, es entregado al pueblo para que le crucifiquen (Lc 23,13-24).

-La petición de las autoridades locales, cuando el gobernador romano Festo sube a Jerusalén (Hch 25,2-3).

-La disposición de Festo a ceder y cambiar el lugar del proceso (Hch 25,4-5.9).

Pablo para obviar la propuesta de Festo y sustraerse al peligro grave que cree acecharle (cf. Hch 25,3), apela al César, lo que Festo aceptó inmediatamente (Hch 25,10-12). En tal ambiente no es extraño ni exagerado el temor martirial de Fp 1,20-23.30; 2,17. Es más, en Cesarea se comprenden perfectamente, bajo el gobierno de Félix, la sucesión de sentimientos y el paso del optimismo por una pronta liberación como refleja Fp 2,24 (cf. Hch 24,23-26) al pesimismo y pérdida de tal esperanza. Hch 24,27 debió ser como un jarro de agua fría apagando la ilusión creada.

Como una situación semejante podía producirse en Éfeso en el caso de una prisión de Pablo y como efecto de la presión popular, no puede declararse esta prueba como definitiva a favor de Cesarea únicamente.

La redacción de la "Carta", tanto si se produjera en la prisión cesariense como en la romana, en las que Pablo estuvo preso por espacio de unos dos años en cada una, no puede asignarse a los comienzos de ninguna de las dos prisiones, como pretendió Lightfoot respecto a la romana en razón de la afinidad lexical y temática respecto a Romanos y de su disimilitud en ambos aspectos con Colosenses y Efesios. Tal datación hay que desecharla por diversas razones:

-Se requiere un cierto espacio de tiempo tanto para el progreso del Evangelio como para el desarrollo de la hostilidad contra Pablo de que da cuenta Fp 1,12-19.

-El intercambio de mensajes y noticias precisa también un período prolongado de meses, si la "Carta" se escribiera desde Roma o Cesarea, harto menos si se hiciera desde Éfeso o Corinto.

-El desenlace de su situación parece estar a punto de producirse (Fp $2,23 \mathrm{~s}$ ); si es consecuencia de finalizar el proceso, hay que esperar al final de la prisión romana (Hch 28,30); si estuviera determinada por las perspectivas de una liberación por falta de pruebas contra Pablo, se podría pensar en Cesarea y en un período avanzado de su estancia en esta ciudad.

Otro argumento frecuentemente esgrimido para reclamar el origen romano de Filipenses, son los saludos que Pablo transmite a la comunidad 
de Filipos de parte de "los de la casa del César" (4,22). Debe tratarse sobre todo de esclavos y libertos, que trabajaban en la administración de los bienes de la casa imperial, ya que a partir de Augusto tanto la casa imperial como miembros de la misma poseían propiedades privadas y negocios en el Oriente. Herodes el Grande, por ejemplo, dejó en su testamento:

-A Augusto diez millones de dracmas de plata, gran cantidad de vasos de oro y plata y custosísimos vestidos

-a Livia (Julia) cinco millones de dracmas

-a su hermana Salomé las ciudades de Yamnia y Toparquía, Azoto, Arqueláis y el palmeral de Fasaelis. A su vez Salomé a su muerte legó estas propiedades a Livia y esta a su hijo Tiberio. Esto explica la presencia de un "epítropos" en Yamnia como afirma Josefo (Ant 17,8,1; 18,2,2; Bell 2,167168).

De la presencia de esas personas ligadas a la casa imperial fuera de Roma da cuenta una inscripción hallada en Éfeso en 1871, que dice:

"Curam agunt collegia lib(ertorum) et servorum domini $n$ (ostri) Aug(usti) i(nfra) s(cripta)" 11 .

\section{B) Reacciones de la comunidad local ante el prisión de Pablo}

El encarcelamiento de Pablo ha causado en la comunidad donde se encuentra preso una doble reacción:

-a la mayor parte de la comunidad la prisión de Pablo le ha llevado a mostrarse más intrépidos para proclamar el mensaje sin temor, sabiendo que a Pablo se le había encargado la difusión del Evangelio (Fp 1.14.16)

-unos pocos de esa misma comunidad se dejan arrastrar por la rivalidad al dedicarse a anunciar también a Cristo. Creen que al obrar así, tornan más dura la prisión a Pablo (Fp 1.15.17).

Esta situación de animosidad y ojeriza por parte de un grupo minoritario de la comunidad local trataron O. Cullmann ${ }^{12}$ y T. Hawthorn ${ }^{13}$ de aplicarlo a la comunidad de Roma, apoyándose en 1 Clem 5, 2-7:

"Por emulación y envidia (-dià dselon kaì phthónon-) fueron perseguidos los que eran máximas y justísimas columnas de la Iglesia y sostuvieron combate hasta la muerte. Pongamos ante nuestros ojos a los santos apóstoles. A

11. G.S. Duncam, St. Paul's Ephesian Ministry, London 1929, 110; H.-G. Plflaum, Carrières procurationienes equestres sous le Haup-Empire romain, 4 vols. Paris 1960-61; O. HIRSCHFELD, Der Grundbesitz des römisches Kaiser in den ersten drei Jahrhunderten, en Kleine Schriften, Berlin 1913, 516-575; cf. FILON, Leg. 30 (199-202).

12. O Cullmann, Peter, Disciple, Apostle, Martyr, London 1953, 104ss.

13. T. HAWTHORN, Philippians 1,12-19. With special reference to vs. 15.16 .17 , ExpT 62 (1950-51) 316-317. 
Pedro, quien por inicua emulación (-dià dsēlon-) hubo de soportar, no uno ni dos, sino muchos más trabajos; y después de dar así su testimonio, marchó al lugar de la gloria que le era debido. Por la envidia y rivalidad (-dià dselon kaì érin-) mostró Pablo el galardón de la paciencia. Por seis veces fue cargado de cadenas; fue desterrado, apedreado; hecho heraldo de Cristo en Oriente y Occidente, alcanzó la noble fama de su fe; y después de haber enseñado a todo el mundo la justicia y de haber llegado hasta el límite del Occidente y dado su testimonio ante los príncipes, salió así de este mundo y marchó al lugar santo, dejándonos el más alto dechado de paciencia".

Sobre este pasaje debe observarse:

-Que el término clave en todo el párrafo es "dsêlos", que se encuentra ausente del pasaje correspondiente: Fp 1,15.

-Que 1 Clem 5,2-7 no atribuye la actitud que O. Cullmann presupone ni a la comunidad cristiana de Roma ni a los cristianos de otras partes. Se trata de un resumen general de la vida de ambos apóstoles y por otros datos del contexto se presupone, que los personajes causantes de tales sufrimientos son ajenos a la comunidad cristiana.

La cita no ayuda nada, por tanto, a la interpretación de Fp 1,14-17 y tampoco parece aportarle más luz la concepción de T. Hawthorn:

Éste presenta a los predicadores de Fp 1,15.17 -gente que se ha puesto a predicar arrastrados por la envidia y la rivalidad-como ajenos a toda controversia religiosa, empeñados únicamente en una polémica contra el Estado Romano. El Evangelio era presentado como mensaje antiimperialista, tal vez a semejanza de Hch 17,7-8. Con ello se promoverían choques con la potencia ocupante, provocando la persecución y propiciando el martirio como parte de los sufrimientos finales, para forzar la intervención definitiva de Dios. Su actitud sería semejante a la de los zelotas y se explicaría perfectamente en la Cesarea del 59 a raíz de los desórdenes ocurridos en esta ciudad entre judíos y griegos (Josefo, Ant 20, 8, 7), pero no en Roma. Esta situación pondría naturalmente en dificultades a Pablo con las autoridades locales y no ayudaría nada en su proceso.

Pero, si se hubiera tratado de una politización del Evangelio, ¿no hubiera denunciado Pablo una tal interpretación, sobre todo después de haber escrito $\mathrm{Rm}$ 13, 1-7? No obstante, no existe una tal denuncia ni ninguna otra acusación de que la predicación de estos envidiosos propalase error doctrinal alguno. Debe tenerse además en cuenta que la "envidia" y la "rivalidad" están dirigidas contra Pablo y no contra el Estado Romano ${ }^{14}$. Menos aceptable es la propuesta de F.C. Sunge ${ }^{15}$ de ver en estos predicadores a antagonis-

14. T. W. MAnson, The Date of the Epistle to the Philippians, BJRL 23 (1939) 182-200.

15. F.C. SYNGE, Philippians and Colossians, London 1951, 24 s. 
tas de los judíos, a los que denunciarían como represalia por cuanto han hecho padecer a Pablo y por su intento de asesinarle (Hch 20, 3; 21, 27); contra esta interpretación sigue siendo válida la crítica de Manson. Tampoco parece aceptable la tesis de R. Jewett ${ }^{16}$ si se la toma en sentido extremo de identificación de estos predicadores con los judaizantes cual éstos aparecen en 2Cor, Gál, Rm 1-4; Fp 3,1b-4,1, pues Pablo les habría acusado de errores doctrinales, lo que no sucede aquí. Podría en cambio aceptarse esta propuesta si sólo se trata de simpatizar con ciertas ideas de esa corriente, relativas al concepto de "apóstol" y su comportamiento y aún la observancia de la Ley, como se desprende de Hch 21,20-22.24.

Esta situación de divisiones dentro de la comunidad les parece a algunos decisiva para adscribir el origen de la "Carta" a Roma. Ciertamente que este dato elimina las pretensiones de Éfeso como lugar de origen del escrito, ya que la comunidad efesina fue fundada directamente por Pablo y no se constata que en la misma se discutiera su autoridad como sucedió en Corinto (1Cor 1,11-17; 3,1-10; 4,1-5) o en Galacia. La hipótesis de G.S. Duncan ${ }^{17}$, de que en Éfeso pudo formarse un partido en torno a Apolo, como había ocurrido en Corinto, es enteramente gratuita. Hch 20,30 no tiene aplicación aquí, pues fuera de anunciar allí Pablo un hecho futuro, la predicación de los allí aludidos se presenta como herética, dato ausente de Fp 1,15.17.

La identificación de la comunidad descrita en Fp 1,12-18 con la de Roma, como se hace ordinariamente, no me parece fundamentada suficientemente y menos lo que escribe F.W. Beare ${ }^{18}$ :

"Es enteramente comprensible que cuando Pablo llegó a Roma, encontró, que su recelo estaba entera y desgraciadamente justificado respecto a algunos líderes locales (-tal vez más de algunos de sus seguidores-), envidiosos de los dones sobrenaturales y de su fama, y que intensificaron su actividad mezclada con otros motivos y con celo no enteramente puro".

Pero esta explicación, deducida básicamente de Fp 1,15.17 es contraria a los datos que nos proporcionan Hch 28,15. Pablo para esta comunidad en modo alguno aparece como "persona no grata". Por otra parte, no parece tampoco correcto deducir de Rm 14,1-15,13, que en la comunidad de Roma se dieran divisiones, pues estas páginas de Romanos no son descripción de la situación de la comunidad de Roma, que Pablo desconoce, sino exposición de temas, que en el momento de escribir la Carta a los Romanos son objeto

16. Conflicting Movements in the Early Church as Reflected in Philippians, NT 12 (1970) 362-390.

17. S. DunCAN, Ephesian Ministry, London 1929, 273s.

18. F.W. BEARE, A Commentary on the Epistle to the Philippians, London 1959, 17. 


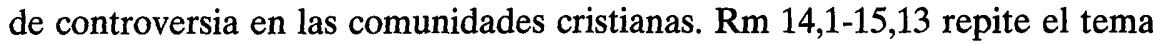
general de 1 Cor 8,1-11,1, aunque con nueva exposición y argumentos.

La manida división de la comunidad cristiana de Roma no parece estar sustentada por un argumento serio. Para aplicar Fp 1,12-18 a la comunidad de Roma, antes hay que demostrar que Filipenses se escribió verdaderamente desde Roma y no usar ese pasaje pretendiendo demostrar la tesis de un tal origen, pues en ese caso no prueba nada.

Se ha dicho que el número y tipo de comunidad que describe Fp 1,12-18 no puede corresponder a la comunidad cristiana de Cesarea, pues el pasaje de Filipenses supone un centro suficientemente amplio, como para que puedan darse interpretaciones diferentes de la fe cristiana e incluso corrientes distintas. Precisamente la comunidad cristiana cesariense se encuentra inmersa en tal situación más que ninguna otra de las propuestas. Cesarea era una ciudad de la costa palestina fuertemente helenizada, en la que la reclamación de la igualdad de derechos por parte de los judíos residentes provocó choques con los griegos y graves desórdenes en el 59 (Fl Josefo, Ant 20,8,7). La comunidad cristiana de Cesarea estaba constituida en su mayoría por helenistas, siendo uno de sus dirigentes el evangelista Felipe, en cuya casa Pablo y sus acompañantes se habían hospedado en el viaje a Jerusalén (Hch 21,8-15). La orientación teológica fundamental de la comunidad debía corresponder a la teología del grupo helenista, que consideraba a Pablo como a uno de sus líderes (Hch 24,5); tal vez ello explique de forma adecuada la buena acogida que en el citado viaje esta comunidad dispensó a Pablo y a sus acompañantes y también, que al ver en cadenas al máximo impulsor de sus ideas, se lanzaran ellos decididamente a la actividad apostólica. Pero junto al grupo mayoritario helenistas coexistía también otro grupo menor de cristianos fuertemente influenciados por el grupo fariseo, que dirigía en aquel entonces los destinos de la comunidad madre de Jerusalén y otras comunidades de Judea. Las concepciones de este grupo podían ser las mismas que reflejan Hch 21,20-22.24 y muy próximas en otros aspectos a las de los judaizantes, como sobre la concepción del "ser apostólico" y sobre "el modo" de llevar a cabo la misión. Cuando Pablo llega preso a Cesarea, es normal que ambos grupos reaccionen de modo distinto. Si Colosenses hubiera sido escrita desde Cesarea, un dato vendría a confirmar esta división de la comunidad cesariense, lo que reflejaría también la situación política reinante en la ciudad: en Col 4,10s informa, que "de entre los de la circuncisión" sólo Aristarco, Marcos y Jesús, el "justo”, colaboran con él.

Lo precedente elimina abiertamente a Éfeso y pone en entredicho la tesis romana. 


\section{C) Los viajes}

A. Deissmann ${ }^{19}$ fue el primero en poner de relieve la distancia que separa a Roma de Filipos y los frecuentes viajes que la "Carta" presupone que ocurrieron entre ambas comunidades precedentes a su puesta por escrito. Esto implicaría, que Roma debiera ser excluida como lugar de origen de Filipenses. A esto replicó Lightfoot señalando con precisión las distancias y el tiempo invertido en recorrerlas según los testimonios de escritores antiguos como Ovidio, Horacio y Cicerón; pero sobre todo que la duración de los encarcelamientos de Cesarea y Roma permiten no sólo esos diversos viajes, sino incluso otros más.

Al escribirse Filipenses y de ocurrir esto en Roma, ya habrían tenido lugar al menos cinco viajes, y de haber ocurrido esto en Cesarea o Éfeso cuatro:

-Viaje de Timoteo hasta donde se encuentra Pablo preso, ya que se halla a su lado cuando se escribe Filipenses (Fp 1,1; 2,19-23). El autor de Hechos no le menciona ni acompañando a Pablo en el viaje a Roma ni después a su lado (Hch 27-28). Hubo, pues, de hacer el viaje separado de Pablo, que se había embarcado acompañado de Aristarco y del autor de las Secciones-Nosotros de Hechos. De hacer Timoteo el viaje a Roma separado de Pablo en distinta ocasión y por ruta diferente, pudo entre otros lugares pasar por Filipos, siendo él quien comunicase a la comunidad la infausta noticia, de que Pablo, en vez de ser liberado, había sido enviado a Roma prisionero, para que allí se sustanciase definitivamente el proceso. De no ser así, habría que suponer otro viaje con la noticia de la prisión romana.

-A la noticia de la prisión de Pablo, la comunidad de Filipos reaccionó enviándole subsidios por medio de Epafrodito $(2,25 ; 4,10-20)$. De haber pasado Timoteo por Filipos camino de Roma, Epafrodito y él pudieron hacer juntos el viaje a Roma.

-Llegado al lugar de destino, Epafrodito cayó gravemente enfermo, parece ser que al lado de Pablo, causándole eso dolor a Pablo y la muerte junto a él le hubiera apenado sobremanera. La causa de tal enfermedad no se especifica, pero Fp 2,30 la pone en relación con los servicios prestados a Pablo, diferentes de la ayuda económica, que ellos le enviaron ( $F p$ 2,25-30).

B.S. MacKay ${ }^{20}$ sugiere que Epafrodito cayó enfermo mientras estaba de camino para llevar a Pablo la ayuda de los filipenses. C.O. Buchanan ${ }^{21}$ apoya

19. A. DeIssmann, Zur ephesinischen Gefangenschaft des Apostels Paulus, en Anatolian Studies (Fs. W.M. RAMSAY), Manchester 1923, 121-127.

20. B.S. MACKAY, Further Thoughts on Philippians, NTS 7 (1960-61) 161-170.

21. C.O. Buchanan, Epaphroditus Sickness and the Letter to the Philippians, EvQ 36 (1964) 157-166. 
esta insinuación. En este caso el trecho a recorrer por la noticia de su enfermedad hasta Filipos sería mucho menos. MacKay se apoya para esta sugerencia en Fp 2,30. Pero Pablo diferencia aquí:

-La ayuda enviada por los filipenses de la que le prestó Epafrodito, ayuda que los filipenses no podían prestarle a Pablo. Podría todavía afirmarse que tal ayuda consistió precisamente en llevar a Pablo el subsidio de los filipenses, pero...

-la ayuda de Epafrodito es calificada de "obra de Cristo" y de un "compensar vuestra imposibilidad en el servicio", expresiones que parecen referirse directamente a la actividad apostólica, aun cuando el don de los filipenses sea también calificado en 4,18 como "ofrenda de suave olor, sacrificio que Dios acepta con sumo agrado", significado próximo al de "leitourgia" (cf. 2Cor 9,12; Hch 13,2; Rm 15,21; pero Rm 15,16; Fp 2,17.26).

-Epafrodito se entera, de que a Filipos han llegado nuevas de su enfermedad y se apena por ello ( Fp 2.26).

Se planean además para un futuro inmediato:

-El viaje de Epafrodito a Filipos, siendo él probablemente el portador de la "Carta". Los verbos en pasado deberían ser interpretados como "aoristos epistolares" (Fp 2, 25.28); de otro modo habría que pensar en un retorno de Epafrodito a Filipos un tanto precipitado y anterior a la composición de la "Carta", que posiblemente se había retrasado precisamente a causa de su enfermedad (Fp 2,25-30).-Pablo ha proyectado también enviar en breve a Filipos a Timoteo para que les visite y luego le informe a él sobre su situación (Fp 2,19-23). Tal viaje tendrá lugar en cuanto él vislumbre el desenlace de su situación (Fp 2,23).

-Él mismo espera hacerles pronto una visita (Fp 2,24; cf. Flm 22).

Si los viajes primeramente mencionados ( -4 al menos-) se realizaran desde Éfeso o Cesarea, no es necesario incluir entre los mismos el viaje de Timoteo, pues en ambos casos Timoteo se encontraba al lado de Pablo.

La distancia a cubrir en los viajes desde los supuestos lugares de prisión de Pablo: Corinto, Éfeso, Cesarea y Roma, es enteramente diferente:

-De Roma a Filipos hay unas 730 millas y atravesar en nave el Adriático, en lo que solía invertirse un mes entero. La distancia a cubrir en tierra firme es de unos $1.080 \mathrm{~km}$;, pues la milla romana equivalía a $1.479 \mathrm{~m}$. Se distribuye así:

-Roma-Bríndisi distan unas 360 millas según Estrabón (VI, 283) y de 358 según el Itinerario Antonino (49.51.54).

-Dyrrhachium-Tesalónica distan 267 millas según Polibio (Estrabón, VI, 323), 269 según el Itinerario Antonino y 279 según la Tabla Peutinger. 
-Tesalónica-Filipos distan unas 100 millas según el Itinerario Antonino (152.157); en cambio Plinio (Hist. Nat. 14,18) cifra la distancia entre Dyrrhachium y Filipos en unas 325 millas.

El tiempo necesario para cubrir esta distancia se ha calculado muy diversamente:

-Lightfoot calcula entre 30-35 días, invirtiendo de Roma a Bríndisi 15-16 y otro tanto de Cyrrhachium a Filipos a una media de $231 / 2$ millas por día (=34 km.).

-R.P. Martin y P.N. Harrison le conceden una duración mayor: entre 7 y 8 semanas, aunque la primera cifra les parece la más adecuada. Pero esta duración parece muy exagerada, pues hay que tener en cuenta:

-que los romanos habían logrado una gran seguridad para sus vías de comunicación con los puestos de guardia a intervalos fijos y las patrullas que continuamente circulaban por ellas, cuidando las autoridades de que estuvieran siempre a punto (L. Casson., C.H. Dodd, P.N. Harrison; R. Chevalier, M. Alonso, J. Bernard, J. Siat).

-Que antiguamente la gente estaba acostumbrada a caminar. Ovidio espera que sus libros lleguen de Bríndisi a Roma en un plazo no superior a 10 días y eso haciendo el viaje sin prisas (Ep. Pont. IV, 5,8) y Horacio informa que viajando muy lentamente, hizo el viaje de Roma a Bríndisi en 16 días (Sat 1,5). Eso supone que esa distancia solía recorrerse en menos tiempo igual debía ocurrir con el espacio que separa a Filipos de Dyrrhachium, pues la distancia es aproximadamente la misma.

-El viaje se hacía a pie o en carruajes confortablemente equipados, adaptados algunos incluso para dormir; en muchos de los lugares había coches de alquiler. Caso especial constituye el correo estatal, que solía hacer unos $75 \mathrm{~km}$. por día y los mensajeros a caballo llegaban incluso a los $100 \mathrm{~km}$. por jornada ${ }^{22}$; (cf. Cicerón, Ad. Att. III, 9,10).

Pero el problema no es propiamente el de la distancia, aun cuando A. Deissmann ${ }^{23}$ califique los viajes de Roma a Filipos como "monstruosos", sin duda para hacer más aceptable la candidatura de Éfeso por él propuesta. Lo determinante es comprobar si el tiempo invertido en esos viajes es compatible con el tiempo que Pablo permanece en prisión antes de escribir la "Carta", que como indicamos anteriormente, pertenece a un período muy avanzado de la misma. Y tal compatibilidad sí existe (L. Casson, C.H. Dodd,

22. H. KöSTER, Introducción al Nuevo Testaménto, Salamanca 1988, 399.

23. A. DeISSMANN, vide nota 19. 
P.N. Harrison ${ }^{24}$ ya que tanto la prisión cesariense como la romana se prolongaron por espacio de un bienio ( -18 meses al menos la romana, que era el tiempo hábil señalado por Nerón a los acusadores de fuera de Italia para ejercer su acción legal ante el tribunal del César ${ }^{25)}$.

De Éfeso a Filipos la distancia es notablemente más corta. Según los Hechos de los Apóstoles:

-De Tróade a Neápolis y con viento favorable Pablo y sus acompañantes tardaron tres días (Hch 16;11s); con viento contrario y en dirección opuesta invirtieron cinco (Hch 20,6).

-De Tróade a Éfeso podía hacerse el viaje en unos cuatro días (Hch 20,13-16). Por eso la distancia entre ambas ciudades podía cubrirse en unos 8-9 días y los cinco viajes que Deissmann cree descubrir entre ambas ciudades, de ser seguidos podrían necesitar unas seis semanas. Este espacio de tiempo habría que aumentarlo dejando lugar para la enfermedad y recuperación de Epafrodito. El contraste por el tiempo necesario para los viajes entre Roma-Filipos y Éfeso-Filipos es lo que a A. Deissmann le parece decisivo para ubicar en Éfeso y no en Roma la composición de Filipenses. Pero:

-Ocurre que el espacio de tiempo en el cual estos viajes han de realizarse se prolonga por espacio de dos años. El marco es tan amplio, que en el mismo pueden tener lugar incluso otros muchos viajes.

-La tesis efesina tiene en contra algo, a lo que nunca se ha podido dar una respuesta adecuada: el silencio de los Hechos sobre una prisión de Pablo en Éfeso. G.S. Duncan ${ }^{26}$ y otros sostenedores de la localización efesina presentan esta falta de referencia como una laguna, ya que el autor no se encuentra al lado de Pablo durante la evangelización de Éfeso. Si se tratara de una prisión breve y sin consecuencias mayores, sería admisible tal solución; pero como aquí nos encontramos con una prisión prolongada y un proceso que puso en peligro la vida del Apóstol, es más que difícil admitir esta hipótesis, que en realidad no soluciona nada. La misma precisa de otros apoyos.

24. L. CASson, Speed under Sail of Ancient Ships, Transations of the American Philological Association 82 (1951) 136-148; C.H. DoDD, The Mind of Paul: II, en New Testament Studies, Manchester 1953, 96ss; P.B. Harrison, The Pastoral Epistles and Duncan's Ephesian Theory, NTS 2 (1955-56) 260.

25. B.G.U. 638 recto.

26. G.S. Duncan, St. Paul's Ephesian Ministry, London 1929; id., A New Setting for St. Paul's Epistle to the Philippians, ExpT 43 (1931-32) 7-11; Id., The Epistles of the Imprisonment in Recent Discussion, ExpT 46 (1934-35) 293-298; id., Were St. Paul's Imprisonment Epistles written from Ephesus?, ExpT 67 (1955-56) 163-166; id., Paul's Ministry in Asia -the Last Phase, NTS 3 (1956-57) 211-218; id. Chronological Table to Ilustrate Paul's Ministry in Asia, NTS 5 (1958-59) 43-45. 
-Cuando Pablo quiere encontrarse con los dirigentes de la comunidad de Éfeso en el viaje de la "colecta" a Jerusalén, les convoca en Mileto. No parece que esto se deba a un entredicho, que le prohibiera visitar la provincia de Asia, pues Mileto pertenecía a dicha provincia, o Éfeso. En hechos se da únicamente como razón de tal proceder: "no perder tiempo en la provincia de Asia. Se daba prisa a ver si podía estar en Jerusalén el día de Pentecostés" (Hch. 20,16). Que esto sea una nube de humo para ocultar otras razones, es posible, pero necesita pruebas, que lo demuestren y no meras hipótesis. Y tales pruebas no se han dado todavía.

-De Cesarea a Filipos la distancia es mayor, que la de Roma-Filipos, pero al hacerse el viaje por mar el tiempo es sensiblemente inferior. Pablo, partiendo de Filipos después de la fiesta de los Ázimos y deteniéndose 7 días en Tróade, unos 4 en Mileto, 7 en Tiro, 1 en Ptolemaïs y "muchos días en Cesarea", espera estar en Jerusalén para la fiesta de Pentecostés ${ }^{27}$, a no ser que luego renunciara a tal proyecto y el autor de Hechos no nos dé cuenta de ello. La presencia de judíos en Asia y la misma purificación a que Pablo se somete, parecen sugerir sus presencia en Jerusalén para esa fiesta. La distancia a cubrir entre Cesarea y Neápolis podía invertir unas 3 ó 4 semanas, lo cual no es mucho para los cuatro viajes que habría que suponer como anteriores a la composición de la "Carta", habiendo durado la prisión cesariense unos dos años. Estos viajes serían:

-Llevar la noticia de la prisión de Pablo a Filipos.

-Viaje de Epafrodito con la ayuda que la comunidad de Filipos envía a Pablo. Después de llegar junto a Pablo, Epafrodito enferma gravemente.

-Llega a Filipos la noticia de la enfermedad de Apafrodito, consternando a la comunidad.

-Epafrodito se entera de la pena que su enfermedad ha ocasionado a los fieles de la comunidad de Filipos.

En este caso, el que Timoteo se encuentre al lado de Pablo, al escribir éste la "Carta a los Filipenses" (Fp 1,1; 2,19-23), no precisa viaje alguno de Timoteo, pues le había acompañado en el viaje de la "colecta" a Jerusalén (Hch 20,4) y podía encontrarse a su lado desde el principio, al igual que Aristarco. Pablo y Timoteo están igualmente juntos cuando se escriba Colosenses (Col 1,1) y a su lado se encontrará igualmente Aristarco ( $\mathrm{Col} 4,10)$, acompañando a Pablo también a Roma ((Hch 27,2). De Aristarco nada se dice, en cambio, durante la evangelización de Éfeso.

27. G. StäHLIN, Gli Atti degli Apostoli, Bescia 1973, 470. 
Desde el punto de vista de los viajes realizados es indiferente que la "Carta a los Filipenses" se escribiera desde Cesarea o Roma, pues el espacio de dos años rebasa muy ampliamente el tiempo necesario para hacer tales viajes entre estas ciudades y Filipos, incluyendo la enfermedad de Epafrodito, su recuperación y la demora que entre uno y otro pudiera haber tenido lugar. La pretendida creación de la prisión efesina resulta por ello una hipótesis innecesaria.

\section{D) Cuando se escribió durante la prisión}

Si se acepta el origen romano o cesariense (-y habría que aplicarlo también a la hipótesis efesina-), se plantea el problema del "cuándo" en ese lapso de dos años (-o varios meses-) deba datarse la composición de este escrito. ¿Debe fecharse en los comienzos o al final de la prisión? J. B. Lightfoot ${ }^{28}$ cree que debe asignarse a la primera parte de dicha prisión y antes de la composición de Col-Ef. Como razón presenta las numerosas conexiones existentes entre este escrito y Romanos y los relativamente pocos puntos de contacto con Col.-Ef. El ofrece el presente cuadro:

$\begin{array}{lll}\text { Fp 1,3.4.7.8. } & = & \operatorname{Rm} 1,8-11 \\ 1,10 & = & 2,18 \\ 2,8.9 .10 .11 & = & 14,9.11 \\ 2,2-4 & = & 12,10.16-19 \\ 3,5 & = & 2,28 ; 1,9 ; 5,11 ; 12,1 \\ 3,4.5 & = & 11,1 \\ 3,9 & = & 10,3 ; 9,31.32 . \\ 3,10.11 & = & 6,5 \\ 3,21 & = & 8,29 \\ 3,19 & = & 6,21 ; 16,18 \\ 4,18 & = & 12,1\end{array}$

Esta afinidad lingüística y temática la acentuaron todavía más C.L. Mitton ${ }^{29}$ y F. O. Francis-J.P. Sampley ${ }^{30}$, pudiendo observarse que el paralelismo temático está ordinariamente acompañado por el paralelismo lingüístico.

28. J. B. Lightfoor, St. Paul's Epistle to the Philippians, London 1908 ${ }^{17}$, 41-46.

29. C.L. MitTon, The Epistle to the Ephesians, Oxford 1951, 322-332.

30. F. O. Francis.-J.P. SAmpley, Pauline Parallels, Philadelphia (Penns.) Missoula (Mont.) 1975, 288-306. 
Los paralelismos propuestos por F.O Francis-J.P. Sampley confirman que Filipenses posee una gran afinidad temática con todas las Cartas, incluida Filemón, que se suponen escritas antes que ella, mientras que con Col.Ef., si exceptuamos: la introducción epistolar, la acción de gracias, los saludos finales y la bendición conclusiva, tales paralelismos son muy raros ( 2 con Col: Fp 1,27-30=Col 2,4-7; Fp 4,8-9=Col 3,12-17; con Efesios ninguno con la parte llamada doctrinal, en cambio con la parte moral son relativamente frecuentes llegando a 6 pasajes). Esta diversidad parece que se deba, a que después de escrita Filipenses, surgió una problemática enteramente nueva ( $\mathrm{Col}$ $1-2$; Ef 1-3) lo que ha motivado la casi completa ausencia de paralelos con la parte doctrinal. Ello implicaría la prioridad de Filipenses respecto a Colosenses-Efesios, no pudiendo decirse lo mismo respecto a Filemón.

En el paralelismo de 2Cor 11,21b-29 con Fp 3,1b-4,1 y en la identificación de "thlipsis" de 2 Cor 1,8ss. con la prisión efesina se apoyan J. Gnilka, G. Bornkamm y J.H. Michael ${ }^{31}$ para afirmar que Filipenses se escribió antes de 2 Corintios. J.-F. Collange va más allá y la antepone a 1 Corintios, al menos cree que se escribieron con anterioridad: 4,10-20 (-Carta "A"-) y 1,13,1a; 4,2-9 (-Carta "B"-). Los adversarios a los que combate Pablo habrían comenzado su actividad en Filipos, primero de forma solapada (-Carta "B"-) y más tarde abiertamente y de forma violenta (-Carta "C"-), pasando más tarde a Corinto. A ellos aludiría ya Pablo en 1 Cor 15,32 ${ }^{32}$.

'De las semejanzas y diferencias lo único con certeza que puede deducirse es la prioridad o posteridad, pero no la inmediatez. Las semejanzas implican unidad de autor, las diferencias diversidad de tema tratado, de ambiente que rodea la composición del escrito y situación anímica que noticias y acontecimientos provocan en el autor. En el caso de las semejanzas, los contactos pueden ser simples referencias o desarrollos de pensamiento; en el segundo caso indican normalmente una datación posterior. En Filipenses no se dan propiamente desarrollos, sino más bien referencias, lo cual implica que Filipenses es posterior a 1-2Cor. Con todo esto sólo indica la fecha "ante quam non" 33 .

Lo precedente no soluciona, sin embargo, el problema planteado; la composición de Filipenses va precedida, según indicaciones de la propia "Carta":

31. J. GNilka, Der Philipperbrief, Freibur 1968, 22-23; G. Bornkamm, Der Philipperbrief als paulinische Briefsammlung, en: Neotestamentica et Patristica, (Fs. O. Cullmann), Leiden 1962, 199s.

32. J.-F. Collange, L'épître de Saint Paul aux Philippiens, Neuchâtel 1973, 33 s.

33. J. SCHMID, Zeit und Ort der paulinischen Gefangenschaftsbriefe, Freibur 1931, 122ss.; W. Michaelis, Die Dattierung des Philipperbriefes, Gütersloh 1933. 
-Del desarrollo en la comunidad de la localidad donde Pablo se encuentra preso de una hostilidad abierta de un grupo minoritario contra Pablo, manifestándose ésta en unas intenciones no puras en la predicación (Fp 1,15.17).

-De un progreso en la difusión del Evangelio, a lo que se dedica la parte más numerosa de la comunidad (Fp 1,14.16). También entre la guardia y la gente del entorno se ha difundido, que la causa de la prisión de Pablo tiene su origen en el anuncio del Evangelio (Fp 1,13).

-Hay que contar al menos con cuatro viajes entre el lugar de prisión de Pablo y Filipos.

-Debe pasar también un cierto lapso de tiempo para que la enfermedad y convalecencia de Epafrodito tengan lugar; éstas, sin embargo, coinciden en el tiempo con los viajes de comunicación de esa situación a los filipenses y con el de la noticia a Epafrodito, que su enfermedad ha causado hondo pesar en la comunidad filipense. Hạ de contarse además con que Epafrodito recibida esta noticia todavía permaneciera algo de tiempo al lado de Pablo restableciéndose (Fp 2,25-26).

-El desenlace del proceso o situación le parece a Pablo próximo. Si se tratara del proceso propiamente dicho, consiguiente a su apelación al César, habría que mirar hacia el final de su prisión romana ${ }^{34}$. Si, en cambio, Pablo permaneciera todavía en Cesarea, podríamos situarnos en septiembre-octubre del año en que fue apresado o en la primavera del siguiente.

\section{E) Planes para el futuro inmediato}

Pablo pone en conocimiento de los filipenses lo por él proyectado para un futuro inmediato respecto a ellos:

-Enviarles a Timoteo en cuanto vea despejada su situación (Fp 2,23), para tener noticias concretas sobre ellos (Fp 2,14).

-Ir él mismo a visitarles en cuanto le sea posible (Fp 1,26; 2,24).

Pudiera buscarse una equivalencia entre los proyectos de Filipenses y de los que nos dan cuenta los Hechos: 19,21-22:

-El envío de Timoteo (Fp 2,19) podría identificarse con el Hech 19,22 (cf. 1 Cor 4,$17 ; 16,10$ ), pero tiene en su contra:

34. H.J. CADBURY, Roman Law and the Trial of Paul, en The Beginnings of Christiaty, V, London 1933, 297-338; P. L. Pherigo, Paul's Life after the Close of Acts, JBL 70 (1951) 277-284; G. OGG, The Chronology of the Life of Paul, London 1968, cap. 21; J. J. GUNTHER, Paul: Messenger and Exil, Valley Forge 1972, 142ss. 
-Que en Fp 2,19 no se menciona a Erasto. Fuera de Éfeso no se le menciona acompañando a Pablo ni en el viaje de la "colecta" ni en las posteriores prisiones. Se le menciona además de Hch 19,22, enviando saludos en Rm 16,23 y de nuevo en $2 \operatorname{Tm} 4,20$, indicándose de él que se ha quedado en Corinto en una etapa que se presupone posterior. Se ha propuesto que $2 \mathrm{Tm}$ 4,20 pudiera hacer una referencia al viaje de la "colecta" y que como Filipenses habría sido escrita desde Éfeso, simplemente omitiría el nombre de Erasto. A primera vista esto parece posible, entrando la enfermedad de Trófimo en Mileto como normal en el desarrollo del viaje. Pero éste debía haberse recuperado muy pronto y hacer él un viaje a Jerusalén, de modo que se encontrase en Jerusalén ya en los días anteriores a la fiesta de Pentecostés (Hech 21,29), lo cual ya no parece tan probable. Además estas noticias sobre Erasto y Trófimo se cuentan a alguien que habiendo acompañado a Pablo en tal viaje parecen superfluas, de referirse a ese viaje.

-La finalidad del viaje de Timoteo es diversa en cada uno de los casos: en uno es conocer la situación de la comunidad de Filipos y llevarle noticias a Pablo de la misma; en el otro es preparar la "colecta".

-En el tiempo a que se refieren Hch 19,21-22 Pablo no podría haber afirmado con verdad, que "todos buscan sus propios intereses y no los de Jesucristo" (Fp 2,21), pues en ese período Pablo está rodeado de colaboradores, dispuestos a cualquier sacrificio por él (Rm 16,4).

-La situación de Pablo cuando escribe Filipenses es bien distinta de la presentan Hch 19,21-22.

-El proyecto de Pablo de ir a Filipos Hch 19,21; 1Cor 16,5), que efectivamente habría realizado (Hch 20,1.3), tampoco parece ser equivalente al deseo que expresa en Fp 1,26; 2,24, ya que la situación del Apóstol es distinta (Fp 2,23).

Algunos comentaristas como M. Goguel, W. Michaelis y J. Gnilka firman, tratando de reforzar las anteriores identificaciones de proyectos entre Filipenses y Hechos, que Pablo no había vuelto a visitar Filipos desde la primera evangelización (Hch 16,12-40). Se apoyan para ello en Fp 1,30; 2,12; 4,15 , textos que 1,26; 2,22 reforzarían. Pero la interpretación de estos textos es unilateral:

- "En mi presencia" está en antítesis con "en mi ausencia" (Fp 2,12; cf. Col 2,5) y en modo alguno es equivalente a "en mi única presencia", no estableciendo la frase en sí alusión alguna al número de veces que Pablo haya visitado Filipos; simplemente se prescinde de este dato.

-También la deducción que se hace de Fp 1,20: “...el mismo combate en que me visteis empeñado y que ahora oís que sigo sosteniendo...", de que sugiera un espacio de tiempo inferior a 8-12 años, es infundada; aquí tampo- 
co entra en liza la cantidad más o menos larga de años que separa a ambos sucesos.

-Igualmente las alusiones a los primeros tiempos de la fe: Fp 1,5; 4,15 tampoco sugieren límites de tiempo (cf. 1Tm 2,12-14; 2Tim 3,11).

Existe, no obstante una dificultad, pues parece que Fp 1,26; 2,24 estén en contradicción con Rm 15,23-24.28, ya que mientras en Filipenses manifiesta Pablo su proyecto de visitar de inmediato en cuanto se vea libre a la comunidad de Filipos, en cambio en Romanos había formulado el proyecto de, una vez entregada la "colecta" dirigirse a España, pasando ante por Roma. Ahora bien:

-Si Filipenses hubiera sido escrita en Éfeso, antes por tanto de Romanos como piensan los sostenedores de la hipótesis efesina, se supone que Pablo hubiera llevado a cabo tales propósitos visitando Filipos incluso dos veces (Hch 20,1.3) y dejando para la etapa posterior a la entrega de la "colecta" la realización de los proyectos de Romanos.

-Si Filipenses hubiera sido escrita desde Cesarea, Fp 1,26; 2,24 reflejaría el ambiente de Hch 24,23.26, que en caso de haberse hecho realidad, podían perfectamente combinarse con $\mathrm{Rm}$ 15,23s.28. De haber obtenido la libertad, Pablo se habría dirigido a Roma para llevar a cabo Hch 23,11, pero pasando antes por Colosas (Flm 22) y Filipos, con lo que se lograría una perfecta combinación de ambos planes.

-El problema se plantea si se supone a Filipenses escrita durante la prisión romana, pues habría que suponer el abandono de los planes de Rm 15,23s.28 y su sustitución por el de Fp 2,24. Para tal sustitución hay que contar con un motivo muy grave. C.H. Dodd ${ }^{35}$ presupone que tal motivo se dio. Aplicando a la comunidad de Roma la situación de división y oposición a Pablo, que delata Fp 1,14-18, concluye que Pablo se vio obligado a abandonar su proyecto de $\mathrm{Rm} 15,23 \mathrm{~s} .28$ posponiéndolo para cuando se presentase una ocasión propicia, no pudiendo contar de momento con la colaboración de la comunidad romana, como había antes proyectado. La visita a Filipos se tornaría urgente a causa de la propagando judaizante (Fp 3,1b-4,1). Pero esta construcción de C. H. Dodd adolece del defecto de creer que.Fp 1,14-18 reflejaba la situación de la comunidad de Roma, sin examinar si tal aplicación la hacía plausible algún dato ajeno a Filipenses, pues de lo que se trata es de saber si esta "Carta" ha sido escrita o no desde Roma. La aplicación de Fp 1,14-18 a la comunidad cristiana romana contradice abiertamente a Hch 28,15 , que es el único dato que sobre el particular poseemos. Además tal reconstrucción de los hechos contradice la tradición de la Iglesia romana,

35. C.H. DodD, The Mind of Paul: II, en New Testament Studies, Manchester 1953, 96. 
que reflejan 1Clem 5,7 y el Canon de Muratori (lin. 38-39), quienes confirman que Pablo realizó el proyectado viaje a España. También la tradición que transmiten las Pastorales, revelan que Pablo se dirigió de nuevo a las regiones de Asia-Grecia, visitando aquellas iglesias ${ }^{36}$.

Como lugar donde se proyectaron estos programas de actuación futura de Filipenses, habría que excluir:

-A Éfeso, pues la situación de Pablo en Hch 19,22 y la de Fp 2,24; cf. Col 4,10 es diferente. También la finalidad asignada a los viajes es distinta.

-A Roma, ya que de otro modo se establecería una contradicción innecesaria entre Fp 2,24; cf. Flm 22 y Rom 15,23s.28, resultando además Fp 2,24 en contradicción con la tradición de la Iglesia romana. Pablo parece reacio al cambio de planes cf. 2 Cor 1,17-22.

Queda solo Cesarea como lugar de composición de Filipenses, que pueda armonizar los proyectos de Rm 15,23s.28 y Fp 2,24, integrar la tradición de la Iglesia romana y dar una explicación adecuada de la división de la comunidad que presupone Fp 1,14-18. Como no se produjo la liberación como se esperaba (cf. Hch 24,23.26), no pudo llevarse a cabo de inmediato el proyecto de Fp 2,24; Flm 22, debiendo posponerlos a la misión en España, pero realizándose también al fin según la tradición que reflejan las Pastorales.

\section{F) El don de los Filipenses}

Estando Pablo en prisión los filipenses le enviaron por medio de Epafrodito una ayuda para socorrer su indigencia. Pero, ¿dónde se encontraba preso Pablo? No parece fuera ni Éfeso ni Roma y sí Cesarea:

-Durante su estancia en Éfeso, Pablo fue obrero de Áquila y Prisca como anteriormente lo había sido en Corinto (Hch 18,3). Según el autor de los Hechos, el mismo Pablo confiesa que su trabajo fue suficiente para cubrir sus propias necesidades, las de sus compañeros e incluso para ayudar a los pobres (Hch 20,33-35). Este testimonio parece excluir que recibiera ayuda externa alguna. En este tiempo él se bastaba a sí mismo (-sin embargo, cf. Fp 4,15-16-).

El argumento aducido con frecuencia para explicar la frase de Fp 4,10b: “...os había faltado ocasión para manifestarlo (el interpes por él)", que sería la extrema pobreza de las Iglesias de Macedonia que se presenta como ejemplo a los corintios para estimular a éstos, no tiene valor aquí, ya que, a pesar

36. C. SpicQ, Les Étitres Pastorales, Paris 1947, 83s. 
de esa pobreza (2Cor 8,2 ), contribuyeron espléndidamente a la "colecta" y envían como portadores de la misma a tres delegados (-a cuatro si en vez de "Derbe" se leyera con "D" "Doberes"-).

Por otra parte en Fp 4,10-20 no existe referencia alguna a la "colecta", cosa extraña de haber tenido lugar contemporáneamente. Además recibir en esa ocasión un regalo, hubiera dado pie para que se le pudiera acusar de buscar mediante la "colecta" su propio interés. Pablo trató de mantener las manos limpias en este asunto y por eso busca que otras personas supervisen y se cuiden de la administración de esa "colecta" (Hch 20,4; 2 Cor 8,19-20).

-Si se supone enviada a Roma la ayuda de los filipenses, habría que empezar por reconocer con J. Murphy-O'Connor ${ }^{37}$, que Fp 4,10b suena a reproche amargo, casi a sarcasmo. En Corinto y en Éfeso él podía valerse por sí mismo y a los tesalonicenses les recuerda su asiduo trabajo para no ser gravoso a nadie (1Tes 2,9 ; cf. 1 Cor 4,$12 ; 9,15.18 ; 2$ Cor $11,7-11)$ y es probable, que en Roma encontrándose en "custodia libera" también pudiera ser autárquico.

-En Cesarea se encuentra en una situación diferente. Recluido en el "pretorio de Herodes" (Hech 23,35) no puede llegar por sus propios medios a subvencionarse sus gastos más perentorios. Es verdad que Félix, ante la confesión del propio Pablo, de que "al cabo de muchos años vine a mi nación a traer limosnas y a hacer sacrificios" (Hch 24,17), podía pensar que se trataba de una persona pudiente, que había hecho fortuna en tierras lejanas y por eso abrigaba la esperanza de que Pablo comprase su libertad (-“esperando que Pablo le diese dinero y por eso le llamaba a menudo para conversar con él": Hch 24,26); pero la situación era bien distinta. Pablo tenía lo que ganaba con su trabajo y aquí eso le era impedido, a pesar de esa poca libertad, que el mismo Félix indica al centurión que le conceda; podían servirle sus amigos, pero no trabajar él. La situación, por tanto, más necesitada de ayuda parece la presente. Desde aquí puede con verdad escribir que "les había faltado ocasión para manifestar (su interés por él)" (Fp 4,10b).

Extraña un tanto que Pablo espere a la recuperación de Epafrodito, para agradecer a los filipenses el obsequio que le han enviado y expresarles su profundo agradecimiento por esta atención tenida para con él. Este don le demostraba el afecto y cariño, que seguían profesándole aquellos macedonios. Pero bien pensadas las cosas, Pablo debía esperar al restablecimiento de Epafrodito, para que, si como enviado especial de los filipenses le había traído a Pablo el don de aquellos, fuera también él el portador del agradecimiento del Apóstol.

37. J. MurPhy.-O'CONNOR, Philippians (Letre aux), DBS VII, col 1219. 
Resumiendo los argumentos anteriores puede concluirse:

a) La prisión al igual que el "pretorio" y "los de la casa de César" pueden referirse tanto a Cesarea como a Roma. Éfeso es una mera hipótesis, creada sobre todo por razón del tiempo necesario para cubrir la distancia entre Roma o Cesarea y Filipos; en los escritos neotestamentarios o de los primeros siglos no se nos ha dejado constancia de una prisión de Pablo en Éfeso, excepto la legendaria de los Hechos de Pablo 6.

La peligrosidad del lugar para la vida de Pablo aboga directamente por Cesarea, donde existía una posibilidad de su entrega a las autoridades locales (Hch 25,2-4.9).

b) Las reacciones de la comunidad en la cual Pablo se encuentra preso, son inconcebibles en Éfeso, comunidad fundada por Pablo, y tampoco parecen propias de la comunidad romana de atenernos a las informaciones de los Hch 28,15 únicas que tenemos sobre el particular. Parecen, en cambio, naturales en Cesarea, donde una parte de la comunidad, aunque minoritaria, estaba influenciada por la corriente farisea de la Iglesia de Jerusalén (Hch 21,20-22).

c) La distancia entre Roma o Cesarea y Filipos no constituye obstáculo alguno en contra de la candidatura de estas dos ciudades, pues el espacio de dos años es más que suficiente e incluso sobrante. La candidatura de Éfeso, que pretendía ser alternativa precisamente en razón del tiempo invertido en esos viajes, resulta innecesaria, pues la "Carta" no pone límite alguno temporal para esos viajes.

d) En los planes para el futuro parece que haya que excluir tanto a Éfeso como a Roma como lugar de origen. La primera, porque a pesar de la pretendida coincidencia con Hch 19,21-22, se trata de planes diferentes y la situación de Pablo es también distinta en ambos casos: el fin que se asigna a los viajes de Timoteo difiere el uno de otro y Pablo en un caso está en libertad y en el otro en prisión. Si tales proyectos se hubieran hecho en Roma, habría que contar con un cambio de planes por parte de Pablo, reacio a ello; según la tradición romana Pablo llevó a cabo el proyecto de Rm 15,23s. 28 y según las Pastorales el de Fp 2,24. Quedaría únicamente Cesarea como lugar de origen de esos planes.

e) El obsequio de los Filipenses es menos conforme con la situación de Pablo en Roma y contrario a la que tuvo en Éfeso y su modo de concebir la evangelización en el mundo griego. En Éfeso, según confe- 
sión propia (Hch 20,33-35), se autofinanciaba y en aquella ocasión hubiera sido inoportuno recibir obsequios particulares cuando se estaba llevando a cabo la "colecta". En Roma hubiera resultado demasiado tardío y además Pablo disfrutaba de una libertad, que probablemente le permitía un trabajo remunerado suficiente para sufragar sus necesidades económicas. En Cesarea, en cambio, se encuentra a espensas de sus amigos y sin posibilidad de realizar trabajo manual alguno.

Los apartados b), d)), e) favorecen claramente a Cesarea y presentan muy serios reparos contra la candidatura de las otras ciudades, determinantes en el caso de Éfeso; en cambio a) y c) son aplicables casi por igual a cualquiera de ellas, excepto en parte a). Puede concluirse, además, que la hipótesis efesina creada en razón del tiempo invertido en los viajes, es superflua, pues el espacio de dos años que duran la prisión cesariense y la romana son espacio de tiempo suficiente para tales viajes.

Se han esgrimido otros argumentos a favor de cada una de las ciudades candidatas a ser el lugar donde se escribió Filipenses:

\section{a) Corinto}

Como lugar de origen de Filipenses le propuso ya G. L. Oeder en 1731 y de nuevo lo ha hecho S. Docks ${ }^{38}$. Tal suceso habría tenido lugar durante la primera estancia de Pablo en esta ciudad (Hch 18,1-18).

-El argumento principal es la identificación de la ayuda, recibida encontrándose ya aquí enviada por los filipenses y que recuerda 2 Cor 11,9 y la que le llevó Epafrodito y de la que da cuenta Fp 4,10-20. La ayuda recibida en Corinto le permite dedicarse totalmente a la predicación según Hch 18,5; pero la ayuda de que habla Fp 4,10-20 encuentra a Pablo en la cárcel (Fp 1,7.13.14.17; 2,23) y son otros los que realizan la labor de anunciar el Evangelio (Fp 1,14-17).

-La polémica anti-judaizante, que caracteriza a Fp 3,1b-4,1 no ha surgido todavía, como demuestra 1 Cor; ésta habló de divisiones e incluso de errores morales y doctrinales, pero nada hace alusión a la tormenta que va a desatarse y a la que responderá con 2 Cor, Ga y $\mathrm{Rm}$. Las apretadas referencias a la polémica por parte de filipenses se comprenden si se suponen conocidos por los filipenses 2Cor, Ga y Rm. Así se explican también mejor las conexiones temáticas y lexicales con estos escritos.

38. S. Docks, Lieu et Date de l'Épitre aux Philippiens, RB 80 (1973) 230-246. 
-En Corinto tiene además Pablo un número considerable de amigos; encontrándose aquí no podría escribir con verdad, que sólo Timoteo está a su lado y que todos los demás buscan sus propios intereses, no los de Jesucristo (cf. 1Cor 16,15-18).

-Tampoco en Acaya, durante la misión, se menciona prisión alguna. La comparecencia ante Galión no va precedida de prisión, ni existe para la vida de Pablo el peligro que denuncia Fp 1,20-21. Este argumento, tanto aquí como en el caso de Éfeso podía obviarse si se aceptara la tesis de T.W. Manson ${ }^{39}$, que Pablo no se encontraba preso cuando escribió Filipenses y que el término "cadenas" debía tomarse como metáfora; pero las afirmaciones de la "Carta" parecen demasiado claras y reiterativas para que puede aceptarse tal hipótesis y las dificultades experimentadas por Pablo en Corinto difícilmente se identifican con lo que dice Fp 1,20-21;2,17.

b) Éfeso

La hipótesis efesina fue propuesta por vez primera por $\mathrm{H}$. Lisco, retomada luego por A. Deissmann y defendida con singular celo por W. Michaelis y G.S. Duncan ${ }^{40}$ consiguiendo la adhesión de numerosos eruditos: H. Appel, M. Albert, B.W. Robinson, K. Lake, P. Feine, M. Goguel, G. Delling, J.H. Michael, W. Michaelis, T.W. Manson. P. Lemerle, P. Bonnard, J.M. González Ruiz, P. Benoit, A. Penna, J. Müller-Bardorff, P. Dacquino, W. Schmithals, G. Bornkamm, P. Feine-J. Behm-G. Kümmel, K.H. Schelkle, G. Friedrich, J. Gnilka, J.A. Fitzmyer, J.-F. Collange; otros reconociendo que en la cuestión del tiempo aporta una abreviación importante se mantienen indecisos como M. Dibelius, R.P. Martin, A.H. McNeil, J.L. Price, y A. Wikenhauser.

La tradición extrabíblica es de escaso valor, pues además de tardía, tiene su origen en una interpretación no correcta de 1 Cor 15,32:

-Una tradición local identifica una torre remanente de la antigua ciudad como lugar donde Pablo habría estado preso.

-El prólogo marcionita de la Carta a los Colosenses afirma: "Después que fue arrestado, les escribió (a los colosenses) desde Éfeso". Pero dicho prólogo no precisa ni el tiempo ni el lugar del arresto, sino sólo que les escribió desde Éfeso. Deducir de la expresión anterior, que el lugar haya que identificarlo con Éfeso y que el tiempo sea el de su actividad en esta ciudad durante

39. T.W. Manson, St. Paul in Ephesus. The Date of the Epistle to the Philippians, BJRL 23 (1939) 184.

40. Cf. notas 5, 19, 26. 
el tercer viaje, es hacer decir al texto más que lo que éste afirma. Colosenses es posterior ciertamente a 1-2 Ts, 1-2 Cor, Ga, Rm como lo demuestran el lenguaje, el estilo y la temática, de la que no existe huella en estos escritos, algunos posteriores a su actividad en Éfeso.

-En los Hechos de Pablo, apócrifos, se habla de una prisión legendaria y de una condena a luchar contra las fieras, para lo cual es conducido al teatro; allí un gran león -que él había bautizado en el desierto de Siria- se acerca a él y le lame los pies, siendo ambos liberados por una gran tormenta de granizo, que ahuyenta a los guardias y espectadores y a ellos les permite abandonar teatro y ciudad cada uno por su parte (c.6). Toda esta trama, comentario a 1 Cor 15,32, es evidentemente legendaria y sin valor histórico alguno.

La posibilidad de una prisión de Pablo en Éfeso, originó la hipótesis del origen efesino de Filipenses, hipótesis que ha tratado de apoyarse en textos como: 2 Cor 11,$23 ; 1$ Cor 15,32 ; Hch 20,18 s; 2 Cor 1,8-10. Pero el hecho de tal prisión es el punto base que hay que demostrar y que realmente ningún argumento llega a probar. No se trata, por otra parte, de que durante su larga estancia en Éfeso estuviera preso e incluso lo estuviera varias veces, sino de una prisión prolongada, en la que su vida llegara a estar en peligro, y esto lo desconocemos totalmente, careciendo de pruebas que la avalen. Se pretende una posibilidad de alternativa, pero los mismos que sostienen esta hipótesis son conscientes de su endeblez y admiten abiertamente que tal prisión es un presupuesto, que ellos deducen de ciertos indicios, que tornan la hipótesis probable:

-En 2Cor 11,23 habla Pablo de "cárceles" y según Hechos antes de la prisión jerosolimitano-cesariense-romana sólo conocemos la brevísima prisión de Filipos (Hch 16,19-39). 1Clem 5,6 confirma que Pablo estuvo 6 veces en prisión. Aunque el plural de 2 Cor 11,23 podía explicarse como un plural literario, pues los otros términos que inmediatamente le acompañan están también en plural, hemos de confesar que carecemos de toda información sobre una prisión efesina, sobre todo con las características que Filipenses presenta:

-Prisión prolongada de no sólo unos días o semanas, sino de meses.

-Prisión en la que su vida se encuentra en peligro.

Un encarcelamiento de estas características difícilmente puede admitirse que hubiera sido silenciado por el autor de Hechos, aun cuando en ese período de la vida de Pablo no se encontrase a su lado (-la sección-Nosotros concluye en 16,17 y no vuelve a comenzar hasta $20,5-$ ). Sobre otros sucesos y menos importantes sí que posee información respecto a este período y la transmite. Los Hechos hablan durante la estancia de Pablo en Éfeso de actos 
de hostilidad (Hch 20,19; cf. 1Cor 15,32; 2Cor 1,8-10; Rm 16,4.7), pero no de encarcelamiento ${ }^{41}$.

1Cor 15,32: "Si sólo por miras humanas luché con fieras en Éfeso, ¿qué provecho tendria?" es sin duda el texto en que más se insiste para fundamentar la hipótesis efesina. La paráfrasis de Collagen: "Si no hay resurrección de muertos, ¿cómo explicáis vosotros que yo haya podido proyectar combatir con las bestias en Éfeso y morir mártir?" no se adapta al texto y que Fp 1,2124 aluda a 1 Cor 15,32 no tiene ningún viso de realidad.

Collange intenta establecer la realidad de la prisión efesina. Para ello afirma que el empleo normal del verbo "thēriomachéo" nada tiene de metafórico en 1Cor 15,32, pues tal sentido se opone al contexto, en el que Pablo aduce como prueba de su fe en la resurrección, el haber pasado por una serie de peligros mortales. ‘Qué papel, se pregunta, podría jugar aquí la mención de luchas teológicas?”. Del mismo parecer son J. Weiss y J. Héring.

Contra la interpretación literal abogan muy poderosas razones, que deben ser tenidas en cuenta. Conviene por ello observar:

-San Ignacio usa el mismo verbo en sentido metafórico:

"De Siria a Roma vengo luchando con las fieras, por tierra y por mar, noche y día, atado como voy a diez leopardos, es decir a un pelotón de soldados; ...con sus malos tratos aprendo yo a ser mejor discípulo del Señor" (Ad Rm 5,1).

Y otro tanto hace Appiano (Bell.civ. 2,21: "hoiois thēríois máchomai". Ignacio distingue estos malos tratos que le causan los soldados, de la lucha posterior en el circo con las fieras ( $\mathrm{Rm} 5,2)$. Esta forma tropológica de hablar es frecuente en el AT y en el NT (cf. Mt 7,15; 10,6.16; Jn 10,1-16; $2 \mathrm{Tm}$ 4,17; $1 \mathrm{Pe} 5,8 ; \mathrm{Fp} 3,3$, etc.). Pablo, al igual que Ignacio, describe de modo vivo por medio de una imagen la hostilidad padecida en Éfeso, lo cual se recuerda también en Hch 20,19.

-Contra una interpretación literal aboga también el que Pablo en 2 Cor 11,23-27 no recuerde tal lucha en la enumeración de las penalidades sufridas en su labor evangelizadora.

-De una condena a combatir contra las fieras le protegía a Pablo su condición de ciudadano romano ${ }^{42}$, siendo las violaciones de esta ley considera-

41. La teoría de J.-F. Collange, o.c., p. 25s., de que Fp 1,12-26 es una defensa de Pablo, pues el desvelar su condición de ciudadano romano no optando por el martirio, tal comportamiento fue mal recibido por la comunidad local, no parece responder al sentido obvio del texto y del contexto. Por otra parte, Pablo escribe a los filipenses, no a la comunidad local, ante la cual propiamente tendría que defenderse, pues es la que se siente decepcionada en la teoría de Collange, no la filipense.

42. Lex Portia: Dig. 28,18.4; C.R. BowEN, "I Fought with Beast at Ephesus", JBL 42 (1923) 59-68; R.E. OsBorne, Paul and the Wild Beast, JBL 85 (1966) 225-230; A.J. MALHERBE, The Beasts at Ephesus, JBL 87 (1968) 71-80. 
das como delitos muy graves ${ }^{43}$; las violaciones deben considerarse como excepciones y no como hecho corriente, al menos hasta la persecución de Nerón. No puede consiguientemente argüirse a favor de una tal condena, que en las Provincias romanas se tenía la manga muy ancha, o que Pablo no hubiera manifestado su condición de ciudadano romano, pues en otras ocasiones sí lo hizo (Hch 16,37-39; 22,25-29; 23,27; 25,10-12). Pablo y Silas lo ocultaron al principio en Filipos bien por considerar que el castigo de los azotes no representaba un peligro para su vida o bien porque no tuvieron ocasión de hacerlo entonces, ya que en Filipos la flagelación y la cárcel no fueron precedidas de juicio y sentencia condenatoria (Hch 16,37), cual es en cambio, el supuesto caso de Éfeso.

Incongruente resulta la postura de Collagen al interpretar Fp 1,12-26 como apología de Pablo, que defiende lo correcto de su proceder al dar a conocer su condición de ciudadano romano, para agilizar el juicio al que estaba sometido y así poder dedicarse al anuncio del Evangelio y el proponer en cambio una condena a combatir con las fieras de la cual le libraba precisamente tal apelación.

G.S. Duncan trata de justificar tal condena de combatir contra las fieras en la situación creada a raíz del asesinato de Julio Silano, siguiendo a la misma un período de anarquía social. Pero si se trató de una condena a muerte, ¿por qué no le ejecutaron? y si de una condena a combatir con las fieras, ¿por qué no la menciona el mismo Pablo en 2Cor 11,23-27?

G.S. Duncan insiste suponiendo que Filipenses fue escrita en Éfeso con ocasión de una crisis ocasionada por la acusación de sacrilegio por robo como delatarían Hch 17,27 (cf. Rm 2,22), poniendo esto en peligro la vida de Pablo. Subsistiendo la crisis, las autoridades habrían juzgado conveniente poner a Pablo bajo "custodia" para protegerle durante las "Artemisia", cuando los sentimientos anticristianos podrían excitarse; sería entonces también cuando Pablo habría escrito Colosenses, manifestando, que por encontrarse en prisión, se ve impedido de realizar su misión (Col 4,3s.) La interpretación de G.S. Duncan de Hch 19,37 no es correcta, pues las palabras del canciller de la ciudad se dicen en referencia a Gayo y Aristarco (Hch 19,29) no a Pablo e indican únicamente que estos dos hombres (se presupone que) son inocentes del doble cargo que se hace ordinariamente a los judíos ( $\mathrm{Rm}$ $2,22)^{44}$ y no que en juicio previo hayan sido ya declarados inocentes de tales delitos.

43. CiCERON, In Verr. 5,62,63,66; EusEBIO, HE 5,1,44.47.50.

44. Josefo, Contra ap. II, 237; Ant 4,8,10. 
Pablo debe referirse en 1Cor 15,32 con la imagen de "luchar con las fieras" a aquella misma situación de persecución, odios, calumnias y asechanzas, que recuerda a los dirigentes de las comunidades cristianas de Éfeso, reunidos con él en Mileto (Hch 20,19). Es curioso que las otras dos descripciones de los peligros que la vida apostólica lleva consigo (2Cor 4,8-12; 6,411) empleen imágenes de combate, acomodándose perfectamente al combate con las fieras, como si esta imagen estuviera profundamente grabada en su ánimo por lo expresiva.

-En 2Cor 1,8-10 confiesa Pablo que estuvo en un gravísimo peligro de perder la vida: "Nos vimos abrumados, tan por encima de nuestras fuerzas, que perdimos la esperanza de seguir viviendo; aceptamos en nuestro interior la sentencia de muerte, para que no confiemos en nosotros mismos, sino en el Dios que resucita a los muertos, que nos libró de un tal peligro de muerte". Estas referencias podrían muy bien reflejar la situación descrita en Fp 1,2124 , siempre que en ninguno de los dos casos el peligro de muerte dependa de un juicio y de una sentencia, a los que ciertamente Pablo no alude en 2Cor 1,8-10.

Este pasaje es, por otra parte, tan impreciso, que nos resulta imposible identificar con certeza el suceso a que se refiere. Su coincidencia con Hch 19,23-41, pues los dos cargos, de los que el canciller de la ciudad declara exculpados a Gayo y a Aristarco, al ser dirigidos por Demetrio contra Pablo (Hch 19,26s.), de haber sido admitidos a trámite y probados, hubieran ciertamente implicado para el acusado la condena a muerte. Como el alboroto fue relativamente breve y no se llevó a cabo una acusación ante los jueces, como el canciller propuso, resulta improbable la identificación entre ambos sucesos. 2Cor 1,8-10 debe, por ello, referirse a algún otro evento en el que Pablo se vio envuelto e ignorado por nosotros. El suceso referido en Hch 19,23-41 tuvo como consecuencia la partida inmediata de Pablo de Éfeso, sin que pueda hablarse de prisión, por lo que resulta imposible relacionarlo con Fp 1,21-24.

-Otros dos casos mencionados en Rm 16,4.7 y ocurridos probablemente en Éfeso, nos dejan perplejos por falta de información ulterior:

-En Rm 16,4 se afirma que Áquila y Prisca se jugaron la vida por salvar la de Pablo. ¿Fue con ocasión del tumulto registrado en Hch 19,23-41 en el intento de ocultar a Pablo? De todos modos aquí tampoco se habla de prisión, por lo que una equivalencia a Fp 1,21-24 es improbable.

-Más problemático resulta el caso de Andrónico y Junias representados como compañeros de prisión (-"synaichmálotous”-). Tal prisión pudo deberse a tumultos promovidos por los judíos (cf. Hch 13,50; 14,5.19; 17,5$8.13 ; 18,12 ; 20,19 ; 21,27 \mathrm{~s}$ ). Aunque "synaichmálotous" no exprese directa- 
mente la simultaneidad, sino únicamente que Andrónico y Junias han estado presos al igual que Pablo, todavía este significado resulta sospechoso, ya que es aplicado a otros dos colaboradores de Pablo: Aristarco (Col 4,10) y Epafras (Flm 23) y de éste en Col 4,12 (-contemporánea de Flm-) se envían también saludos, pero nada se dice, de que el mismo esté o haya estado preso.

De todos modos, en ambos casos estamos en el terreno de la conjetura, al no especificarse en ninguno de ellos ni tiempo ni lugar de la exposición de la vida o de la prisión. Debe considerarse también simple cábala, que Pablo no habría alegado su condición de ciudadano romano para no dejar solos en la cárcel a Andrónico y Junias ${ }^{45}$, ya que éstos no poseían el derecho de ciudadanía romana. En el primero de los casos probablemente estuvo en peligro la vida de Pablo y pudiera tratarse del mismo caso que refiere 2 Cor 1,8 10 , pero en ninguno de ellos se afirma que tal peligro proviniera de un encarcelamiento o de un proceso capital que se hubiera seguido contra él.

-Todavía admitiendo que Pablo hubiera estado preso en Éfeso y que su vida corrió un grave peligro, resulta inexplicable que Pablo no hubiera apelado a su condición de ciudadano romano como hizo en otras ocasiones (Hch $16,37-39 ; 232,25-29 ; 23,27 ; 25,10-12$ ), para impedir una sentencia capital por parte de las autoridades locales. Fp 1,20;2,17 cuentan con la posibilidad de un desenlace fatal de su situación de preso, en que se encuentra. Si Pablo apeló en Filipos a tal condición y en Cesarea esta apelación obligó a suspender el curso del proceso y transferirlo a Roma, no se ve razón por qué no hubiera hecho otro tanto de encontrarse en la misma situación en Éfeso. A J. Schmid le parece esta contradicción en que se incurriría una prueba decisiva contra la hipótesis del origen efesino de Filipenses ${ }^{46}$. Se ha tratado por ello de desvirtuar este argumento:

-W. Michaelis es del parecer que Fp 1,20-24 y 2,17 se refieren a un peligro inferior y a una gravedad menor, de la que se derivaría si Pablo hubiera de ser condenado a muerte. La vida de Pablo no debía estar realmente en peligro, cuando él contempla las dos posibilidades; viday muerte en Fp 1,20$24 ; 2,17$ deben interpretarse como referencias a los peligros mortales a que la vida apostólica expone. Sin embargo, aquí se trata de un peligro distinto al del ministerio apostólico en sí (cf. 1Cor 15,31; 2Cor 4,10s). Los textos de Fp $1,20.30: 2,17 ; 3,11 ; 2 \operatorname{Tm} 4,6$, que repiten la metáfora del sacrificio y la ofrenda son la confesión de un peligro específico y grave. C.H. Dodd ${ }^{47}$ observa con

45. R.P Martin, Philippians, Grand Rapids 1980, 55.

46. J. SCHMID, o.c., p. 107.

47. C.H. DoDD, a.c., p. 103, n. 2. 
atino que aquí se trata de una cuestión de vida o muerte como aparece claro en Fp 1,20, confirmando Fp 1,25 que esa vida puede truncarse como consecuencia de la situación en que Pablo se encuentra inmerso en ese momento, no dependiendo tal conclusión de un cálculo de probabilidades. Pablo cree no obstante, que su vida es tan necesaria para sus comunidades, que Dios hará que escape a la muerte, aunque sea recurriendo al milagro (cf. 2Cor 1,9s.). Esta observación hay que tenerla en cuenta para explicar su fluctuación entre el optimismo y la desesperanza. La desmoralización se produce al contemplar la situación en que se encuentra, pues entraña un peligro real de muerte; y la esperanza de libertad es también firme, porque se apoya en la respuesta de Dios a la plegaria de los filipenses, que imploran su liberación. Pudiera decirse que desde el punto de vista humano la situación se presenta oscura, no así cuando se la contempla a la luz de la fe.

-Pablo se sentiría en peligro, pero no como resultado de la marcha del proceso, sino por el temor a un atentado con su vida. Pero tal peligro ya proviniese de los judíos (cf. Hch 20,18), ya de un tumulto (Hch 19,23-41) era poco probable en Éfeso. Contra ellos, sin embargo, de nada le valdría su condición de ciudadano romano. La situación en que Pablo se encuentra es calificada de "agōn" y es similar a la sostenida en Filipos, diferente, por tanto a un atentado o un tumulto (Fp 1,20).

-Parece también inexplicable que si Filipenses se escribió en Éfeso, antes incluso de 2 Cor o de la 1 Cor, no exista en ella referencia alguna a la "colecta para los santos de Jerusalén" ${ }^{48}$. Esta ausencia es muy llamativa, pues este tema le preocupaba sobremanera a Pablo como él mismo confiesa en Gal 2,10; cf. 1Cor 16,1-4; 2Cor 8-9, y que trató de llevar a cabo disponiendo las cosas durante su permanencia en Éfeso y dirigiendo los movimientos de los que le rodeaban (cf. Hch 19,22; 20,4). Se ha pretendido relacionar la misión de Fp 2,19 con Hch 19,22, pero los objetivos de ambas misiones son diferentes. J.H. Michel ${ }^{49}$ sugiere que las instrucciones para la colecta las habría recibido oralmente Epafrodito, que las transmitiría del mismo modo; J. Gnilka ${ }^{50}$ prefiere que sea el mismo Timoteo el portador de las mismas. En Fp 2,19-23 parece que a Timoteo se le encomienda sólo conocer el estado en que se encuentra la comunidad de Filipos y volver con esas noticias a Pablo, excluyendo 2,21 todo otro acompañante. Según Hch 19,22 Timoteo parte para Macedonia acompañado de Erasto.

48. J. Chmid, o.c., pp. 112-114; P.N. HARrison, The Pastoral Epistles and Duncanis Ephesian Theory, NTS 2 (1955-56) 258s.

49. J.H. MICHAEL, The Epistle of Paul to the Philippians, London 1928, XXII.

50. J. GNILKA, Der Philipperbrief, Freiburg 1968, 24. 
La candidatura de Éfeso parece descansar sobre bases demasiado endebles para sobre ellas fundamentar una hipótesis plausible; es cierto que la estancia de Pablo en esta ciudad debió ir acompañada de calumnias, acechanzas y persecuciones (Hch 20,19), incluso pudieron darse también encarcelamientos, pero no de las características que Fp 1,20-24 presupone. Sobre supuestas lagunas informativas y silencios es imposible cimentar construcciones históricas con visos de certeza.

\section{C) Roma}

La tesis que propugna el origen romano de Filipenses era hasta el s. XX seguida casi unánimemente por los comentaristas. En los títulos que encabezan los manuscritos se señalaba ordinariamente esta procedencia, soliéndose atribuir, excepto Lightfoot, al final de la cautividad romana. Los defensores de este origen son todavía numerosos; baste citar algunos de ellos: Entre los comentaristas: J.B. Lightfoot, E. Haupt, M. Jones, M.R. Vincent, P. Ewald, K. Barth, J.-J. Müller, E.F. Scott, K. Staab, F.W. Beare. En introducciones: R.M. Grant, L. Cerfaux, D. Guthrie, B. Jay. Articulistas como: P.N. Harrison, B.D. Rathjen, B.S. McLKay.

Esta tesis ha sido defendida con particular ardor por J. Schmid y C.H. Dodd. Debo confesar, sin embargo, que las razones aducidas a favor de Roma y a pesar de una tradición multisecular reflejada ya en Marción: "scribens eis a Roma de carcere", no me parecen convincentes. Los argumentos que parten de la mención del "pretorio" (Fp 1,13) y de "los de la casa del César" (Fp 4,22) no pueden aplicarse exclusivamente a Roma, pudiendo hacerse con el mismo derecho a otras ciudades. El argumento que más pudiera inclinar a favor de Roma, es que Pablo espera una pronta liberación (Fp 2,24), aunque también cuenta con la muerte (Fp 1,20; 2,17). Si tal liberación o muerte dependiera exclusivamente de la solución judicial del proceso, entonces ciertamente sería Roma la única con derecho a reclamar ser el lugar de origen de Filipenses, pues Pablo como ciudadano romano no podía ser condenado a muerte más que por el tribunal imperial; pero si tal liberación o muerte no fuera el fruto del proceso capital, la exclusividad de Roma desaparece. Ciertamente Pablo se encuentra preso y sometido a proceso cuando escribe Filipenses, pero liberación o muerte como desenlace de la situación pueden producirse -como resultado de una condena, fruto de un proceso capital. En la "Carta" se afirma que Pablo se encuentra preso y que teme por su vida, estando él dispuesto a derramar su sangre como libación sobre la fe de los fieles de Filipos, pero ni siquiera se insinúa que tal peligro 
provenga del proceso al cual se encuentra sometido. La deducción se hace cuando se identifica la prisión que menciona la "Carta" con la prisión romana, concluyéndose entonces que al estar Pablo sometido a un proceso capital por la imputación de haber profanado el templo (Hch 21,28; 24,6; 25,8), se siente turbado y cuenta también con un desenlace fatal como término del proceso. Como ya no hay lugar a apelación alguna por encontrarse ante los jueces imperiales de Roma, no pudiendo hacer humanamente nada, sólo le resta confiar en que Dios, por las súplicas de los filipenses, le libre del peligro.

Ahora bien, para esa identificación exclusiva hay que demostrar que Pablo no puede referirse a otra prisión y a otra situación diferente. La ansiedad atribuida a Pablo como resultado del proceso en el período romano no es deducible de las indicaciones anteriores de Hch 25,18.25; 26,31.32; 27,3.43; 28,8-10.14.16.18.30-31. Los informes de que era portador el centurión Julio, o el testimonio de éste, si los informes se perdieron en el naufragio, debieron ser muy favorables, pues a Pablo se le permitió vivir en Roma hasta que se sustanciase el proceso en "custodia libera". No parece que durante esa permanencia en Roma se den razones cognoscibles para nosotros en relación con el proceso, que originen tal ansiedad. Fp 1,20ss; 2,17 posiblemente no tenga relación con el proceso romano.

-Como consecuencia de las asechanzas que se tramen contra el preso, al margen del proceso propiamente dicho. Si no se encuentra en Roma y sí en Cesarea, se podían intentar que fuera entregado a las autoridades judías locales como gracia, cosa que ya intentaron estas autoridades cuando Festo subió de visita a Jerusalén (Hch 25,2-3), o seguir cualquier otra estratagema para eliminarle. En la situación concreta de Pablo en Cesarea su vida corría peligro permanente.

Un segundo argumento es que permite aceptar una evolución del pensamiento de Pablo en el tema de la escatología individual (Fp 1,20-23), pues el "irse y estar con Cristo" (Fp 1,23) clarifica el esbozo de 2Cor 5,8b: "morar con el Señor", marcando esto un gran avance sobre el tema de la resurrección final, esclareciendo lo que ha venido a llamarse "período intermedio".

Esta evolución no necesariamente tiene que ser asignada a la prisión romana; en sí sólo exige que sea posterior a 2 Cor, pudiendo estar motivada por la reflexión sobre el retardo de la parusía, coadyuvando tal vez los peligros de muerte que continuamente le acechan y sobre todo las últimas experiencias, permitiéndole una profundización de lo que había escrito a los tesalonicenses: “... a los que han muerto, Dios, por medio de Jesús, los llevará con él” (1Ts 4,14). 
Una dificultad más para ubicar en Roma la composición de Filipenses, es que Timoteo se encuentra al lado de Pablo al escribir la "Carta", apareciendo como corresponsable de la misma (Fp 1,1; cf. 2,19-23). Probablemente estuvo al lado de Pablo en Cesarea, pues le acompañó a Jerusalén en el viaje de la "colecta" en calidad de delegado de las Iglesias de Galacia (Hch 20,4), pero no parece haber hecho el viaje a Roma acompañándole (Hch $27,2)$. Es posible que luego fuera a reunirse con él en Roma, pero carecemos de noticias sobre este particular.

\section{D) Cesarea}

El primero en proponer el origen cesariense de la Carta a los Filipenses fue H.E.G. Paulus de Jena (1799) ${ }^{51}$, respaldándole en 1829 D. Chultz ${ }^{52}$, siguiéndoles luego O. Pfeiderer, O. Holtzmann, F. Spitta, E. Lohmeyer, L. Johson, J.J. Gunther, y es favorab́le a la misma W.G. Kümmel. La prisión en este caso es la padecida en Cesarea de Palestina durante los dos últimos años del gobierno de Félix y hasta que su sucesor Festo se hizo cargo de dicho gobierno (a. 60 ó 61 p. C.). Abarca en la narración de los Hechos de 23,37 a 27,1 .

Como se ha podido observar en la exposición de los primeros argumentos, unos son comunes a las diversas ciudades candidatas, otros a una o dos, pero ninguno puede considerarse como no favorable a la candidatura de Cesarea, e incluso los de las reacciones de la comunidad local, los planes para el futuro y el don de los filipenses están abiertamente a su favor, siempre que nos atengamos a los datos que poseemos y no a especulaciones posibles. En otros casos como la polémica antijudaizante, la evolución escatológica o la conexión literario-temática con Romanos y escritos anteriores, puede considerarse con los mismos derechos que Roma; pero en el caso del peligro grave a que Pablo está expuesto, la esperanza de una posible liberación y la decepción (Fp 1,20-23.26; 2,24) se comprenden mejor en Cesarea (Hch 25,2-3; 25,26.27). Añaden algunos que:

- "Entre cadenas" (Fl 1,7.13,14; 2,23; cf. 2,14; 4,14) se entiende mejor aplicado a la prisión en Cesarea que a la prisión en Roma, donde se reduce la misma a una simple "custodia libera" (Hch 28,16.30s.); en Cesarea, en

51. W. MiCHAELIS, Einleitung in das Neuen Testament, Bern 1961 ${ }^{10}, 205$.

52. D. SCHULZ, ThStK 2 (1829) 612-617. 
cambio, está realmente encadenado (Hch 26,29). En contra de esto se ha urgido que Pablo, al final de los dos años -o 18 meses- de la prisión romana y cuando el proceso se acercaba a su fin, debió ser sometido a una "custodia militaris" estricta y sería nuestra "Carta" el testigo de ese cambio. Pero esto es mera suposición sin pruebas que lo respalden.

-La insistencia de los judaizantes en la necesidad de que los gentiles cristianos se sometieran a la circuncisión para resultar miembros efectivos de Israel, podría en parte deberse a la presión nacionalista, que están desarrollando ciertos grupos, como más tarde harán los zelotas. Estos grupos ya habían expresado su odio a Pablo y habían intentado asesinarlo (Hch 21,30; 23,12-14; 25,2s.11), por figurar como el que incitaba a desertar de Moisés y a no circuncidar a los hijos (Hch 21,21). Pablo no se amedrentó, sino que puso en guardia a sus fieles contra los judaizantes y sus doctrinas (Fp 3,1b-4,1) y con ello contra la pretensión de lealtad nacional, que debía expresarse mediante la circuncisión carnal. El Apóstol sabe, sin embargo, que el odio de estas personas es tenaz y que mientras se encuentre en Cesarea, su vida corre peligro, que es lo que reflejan algunos pasajes de la "Carta" como Fp $1,20-23 ; 2,17$. En la comunidad cristiana de Cesarea debía haber un grupo notable, pero minoritario (Fp 1,14) de judíos, influenciados por las ideas de estos grupos nacionalistas. El cambio que se observa de Hch 15,13-19 a 21,20-24 refleja también ese influjo y si bien no aparezcan los errores de los judaizantes cristianos de 2 Cor, Ga y Rm, sí, en cambio, un judaísmo exacerbado, que veía las posiciones de Pablo como una traición político religiosa; no es extraño, pues, que el grupo judío se negara a colaborar con Pablo y tratase con ello de marcar distancias respecto a él. Si Col 4,10 perteneciese a un período próximo y al mismo lugar que Filipenses, pondría de manifiesto hasta qué extremos llegó este distanciamiento y cuán solo tenía que sentirse aquí Pablo; Fp 2,21 sería en este caso no sólo el reproche de un corazón decepcionado, sino también el reflejo de una triste situación. En estos momentos de su calvario, sólo Timoteo se encuentra a su lado y sólo en él puede desahogar su espíritu atribulado. Probablemente en ninguna otra ciudad, de las que se disputan el honor de ser origen de la Carta, pudo sentirse tan solo. Hay que contar con que, al prolongarse la prisión, cada uno de los delegados que le habían acompañado en el viaje de la "colecta", excepto tal vez Timoteo, Aristarco y algún otro, fueran volviéndose a la comunidad que les delegó, quedando Pablo cada vez más solo, aunque empezase un ir y venir de gentes que le traían noticias de las diversas comunidades. Así llegaron informes de la perturbación que la predicación de ciertos maestros ha causado en Colosas, vino Epafrodito con ayuda de la comunidad de Filipos y llegó hasta él Onésimo buscando refugio, dando cada uno de estos casos ori- 
gen a una carta. Pero el número de personas que se mantuvo a su lado debió de llegar a ser muy pequeño, pues cuando parte para Roma, sólo le acompañan el autor de los Hechos y Aristarco (Hch 27,2). Timoteo, pudiera ser que hubiera partido hacia Filipos con la noticia de su traslado a Roma, pudiendo realizar el proyecto de Fp 2,19-23 y por eso no hallarse a su lado en el momento de embarcarse, o al menos no partió con él en ese momento por motivos desconocidos para nosotros.

-La afirmación de Fp 1,13 es más fácilmente aplicable a Cesarea que a Roma, donde los pretorianos llegan a unos 9.000, y lo mismo cabe decir de "los de la casa del César" (Fp 4,22).

Extraña, sin embargo, que si se escribió Filipenses desde Cesarea, no se nombre a Felipe, en cuya casa había descansado Pablo en el reciente viaje de la colecta (Hch 21,8), lugar donde se había predicho a Pablo su presente prisión (Hch 21,10-11). La razón podía ser para Pablo que este personaje era desconocido para la comunidad de Filipos, no mencionando tampoco las comunidades por las que ha pasado; a sus colaboradores los abarca a todos en un "os saludan los hermanos que están conmigo" y a los fieles de la comunidad local los reúne en un "todos los creyentes" (Fp 4,21s). Lucas tenía razones especiales para individualizar a Felipe -cosa que no ha hecho con ninguna otra persona de las comunidades que han visitado en el curso del viaje a Jerusalén-. De Felipe había ya hablado anteriormente en (Hch 6,5; 8,5-13. 26-40) y lo había dejado en Cesarea (Hch 8,40). Felipe precisamente pudiera ser una de sus fuentes de información para buena parte de su Evangelio y de los Hechos, autor de la llamada "fuente cesariense".

La discusión sobre el lugar de origen y por consiguiente de la fecha de la composición de Filipenses ha llegado, según Dibelius, a un punto muerto. Si es cierto que su composición en Roma tropieza con graves dificultades, la hipótesis efesina, propuesta por gran número de autores como alternativa, choca con escollos todavía mayores. La única que parece poder superar las pruebas del examen es Cesarea, pero la mayoría de los investigadores la rechazan casi "a priori". Tal vez sea preciso reexaminar las pruebas como hemos tratado de hacer nosotros.

A. PÉrez Gordo, CP Las Presas-Santander 


\section{BIBLIOGRAFÍA}

1. Fuera de los comentarios, que al principio suelen tratar el tema de modo más o menos extenso puede consultarse la siguiente bibliografía:

P. Antoine, Ephèse, DBS II (1934) 1078-1104; G. R. Beasley-Murray, Philipians, PC (1962) 985-989; G. Delling, Philipperbrief, RGG ${ }^{3}$ V (1961) 333-336; J. MurphyO'Connor, Philippiens (Letre aux), DBS VII (1966) 1211-1233; E. Oberhummer, Egnatia Via, PW V (1905) 1988-1993; P. Romanelli, Egnazia Via, Enclt XIII (1950) 592-593.

L. Heuzey-H. Daumet, Mission archéologique de la Macédonie, Paris 1876; J. T. Wood, Discoveries at Ephesus. Including the Site and Remains of the Temple of Diana, London 1887; R. Steinmetz, Die zweite rõmische Gefangenschaft des Apostels Paulus, Leipzig 1898; F. Haverfield, On the Strategot of Philippi, JTS 1 (1900) 434435; V. Lisco, Vincula Sanctorum. Ein Beitrag zur Erklärung der Gefangenschaftsbriefe des Apostel Paulus. Berlin 1900; W. M. Ramsay, On the Titles of the Magistrates at Philippi, JTS 1 (1900) 114-116; O. Hirschfeld, Die kaiserlichen Verwaltungsbeamten bis auf Diokletian, Berlin 19052, 18-29; D. G. Hogarth, Excavations at Ephesus. The Archaic Artemisia, London 1908; W. Lütgert, Die Volkommenen im Philipperbrief und die Enthusiasten in Thessalonich, Gütersloh 1909; M. Albertz, Überdie Abfassung des Philipperbriefs des Paulus zu Ephesus, ThStKr 83 (1910) 551-594; R. Bultmann, Der Stil des paulinischen Predigt und die kynisch-stoische Diatribe, Göttingen 1910; B. W. Robinson, An Ephesian Imprisonment of Paul, JBL 29 (1910) 181-189; M. Goguel, La date et le lieu de composition de l'épitre aux Philippiens, RHR 66 (1912) 330-342; O. Hirschfeld, Der Grundbesitz des römischen Kaiser in der ersten drei Jahrhunderten, en: Kleine Schriften, Berlin 1913, 516-575; J. S. Reid, The Municipalities of the Roman Empire, Cambridge 1913; G. Ball, The Epistle to the Philippians: A. Reply, Exp 8 (1914) 143-154; M. Jones, The Integrity ot the Epistle to the Philippians, Exp 8 (1914) 457-473; K. Lake The Critical Problems of the Epistle to the Philippians, Exp 8 (1914) 481-493; P. Feine, Die Abfassung des Philipperbriefes in Ephesus, Gütersloh 1916; H. Coppieters, Saint Paul fut-il captif à Ephèse pendant son troisième voyage apostolique?, RB 16 (1919) 404-418; C. R. Bowen, Are Paul's Prison Letters from Ephesus?, AJT 24 (1920) 112-135; J. H. Michael, The Philippian Interpolation -where does it end?, Exp 19 (1920) 49-62; id, The First and Second Epistle to the Philippians, Expt 34 (1922-23) 106-109; Ch. Picard, Les dieux de la colonie de Philippes vers le $1^{\text {er }}$ siècle de notre ère d'après les Exvoto Rupestres, RHR 86 (1922) 117-201; A. Deissmann, Zur ephesinischen Gefangenschaft des Apostels Paulus, en: Anataolian Studies (Fs. W. M. Ramsay), Manchester 1923, 121-127; J. H. Michael, Two brief marginal notes in the text of Philippians, Expt 35 (1923-24) 139-140; M. Goguel, Introduction au Nouveau Testament, IV, 1, Paris 1925, 369-417; W. Michaelis, Die Gefangenschaft des Paulus in Ephesus und das Itinerar des Timotheus, Gütersloh 1925; H. Beyer, Die Zeugnisse des Philiperbriefes von A. T., Nach dem Gesetz und Zeugnis 28 (1928-29) 372s; E. Brandtspengler, Lebensgestaltung: Eine Einleitung in die Gedanken des Philipperbriefes, Leipizg 1028; W. Michaelis, The Trial of St. Paul at Ephesus, JThSt 29 (1928) 368-375; H. G. G. Moule, Philippian Studies, London 1928; G. S. Duncan, St. Paul's Ephesian Ministry, 
London 1929; R. Tonneau, Ephèse au temps de St. Paul, RB 38 (1929) 5-54. 321-363; P. v. Imschoot, Où fit écrit l'épitre aux Philippiens?, CollGand 17 (1930) 79-85; id, S. Paul et l'Église de Philippes, collGand 17 (1930) 109-115; G. S. Duncan, A New Setting for St. Paul's Epistle to the Philippians, ExpT 43 (1931-32) 7-11; J. de Keulenaert, Argumentum epistolae ad Philippenses, CollMechl 5 (1931) 230-231; J. S. Schmid, Zei und Ort der paulinischen Gefangenschaftsbriefe, Freibur 1931; H. J. Cadbury, Roman Law and the Trial of Paul, en: F. J. Foakes Lackson-K. Lake, The Beginnings of Christianity, London 1933, 297-338; W. Michaelis, Die Datierung des Philipperbriefs, Gütersloh 1933; O. Roller, Das Formular des paulinischen Briefe, Stuttgart 1933; G. S. Duncan, The Epistles of the Imprisonment in Recent Discussion, ExpT 46 (1934-35) 293-298; O. Schmitz, Aus der Welt eines Gefangenen, Berlin 1934; A. J. Fersturière, Le monde gréco-romain au temps de Notre Seigneur, I-II, Paris 1935, 77-83; O. Linton, Zur Situation des Philipperbriefes, en: Coniectanea Neotestamentica, II, LeipizgUppsala 1936, 9-21; P. Joüon, Notes philologiques sur quelques versets de l'épitreaux Philippiens, RSR 28 (1938) 89-93. 223-233. 299-310; T. W. Manson, St Paul in Ephesus. The Date of the Epistle to the Philippians, BJRL 23 (1939) 1821-200; W. A. McDonald, Archaeology and St. Paul's Journeys in Greek Lands, BA 3 (1940) 18-24; B. Brinkmann, Epistolae captivitatis S. Pauli num Ephesi scritae sint, VD 21 (1941) 921; T. Torrance, St Paul at Philippi: Three Startling Conversions, EvQ 13 (1941) 6264; K. Wuest, Philippians in the Greek Text for the English Reader, Grand Rapids 1942; P. Collart, Philippes, ville de la Macédonie depuis ses origines jusqu'à la fin de l'époque chrétienne et byzantine, Paris 19452; J. Curran, Tradition and the Roman Origin of the Captivity Letters, ThSt 6 (1945) 163-205; P. Lemerle, Philippes et la Macédonie orientale à l'époque chrétienne et byzantine, Paris 1945; D. W. Riddle-H.H.Hutson, NT Life and Literature, Chicago 1946; A. Cotter, The Epistles of the Captivity, CBQ 11 (1949) 370-380; L. Casson, Speed under Sail of Ancient Ships, Transactions of the American Philological Association 82 (1951) 136-148; S. Nikolaidès, Paul in Macedonie orientale, en: Paulus-Hellas-Oikumene, Athènes 1951, 146-160; L. P. Pherigo, Paul's Life after the Close of Acts, JBL 70 (1951) 277-284; J. Könn, Die Macht der Persönlichkeit, Einsiedeln 1952; E. Peterson, Apostel und Philipperbriefes, Freiburg i.B. 1952; A. N. Sherwin-White, Early Persecutions and Roman Law Again, JTS 3 (1952) 199-213; C. H. Dodd, The Mind of Paul: II, en : New Testament Studies, Manchester 1953, 85-108; J. Jeremias, Zur Gedankenführung in den paulinischen Briefen, en: Studia Paulina (Fs J. de Zwaan), Haarlem 1953, 146-154; G. Ogg, A New Chronology of Saint Paul's Life, ExpT 64 (1952-53) 120-123; G. S. Duncan, Were St. Paul's Imprisonment Epistles written from Ephesus?, Expt 67 (1955-56) 163-166; G. Friedrich, Der Brief eines Gefangenen. Bemerkungen zum Philipperbrief, MonatsPastoralth 44 (1955) 270-280; P. N. Harrison, The Pastoral Epistles and Duncan's Ephesian Theory, NTS 2 (1955-56) 250-261; C. L. Mitton, The Formation of the pauline Corpus of Letters, London 1955; W. Rees, St. Paul first Visit to Philippi (Act 16,1140), Script 7 (1955) 99-105; G. S. Duncan, Paul's Ministry in Asia - The Last Phase, NTS 3 (1956) 211-218; G. Friedrich, Lohmeyer's These über das paulinischen Briefpräskript Kritisch beleuchtet, TLZ 81 (1956) 343-346; L. Johnson, The Pauline Letters from Caesarea, ExpT 68 (1956-57) 24-26; R. S. Kinsey, With Paul in Grece, Nashville (Tenn.) 1957; J. Müller-Bardorff, Zur Frage der literarischen Eincheit des Philipperbriefes, WZJena 7 (1957-58) 591-604; W. Schmithals, Die Irrlehrer des Philipperbriefes, ZthK 54 (1957) 297-341; P. Dacquino, Data e provenienza della lettera ai Filippesi RiBi 6 (1958) 224-232, G. S. Duncan, Chronological Table to IlIustrate 
Paul's Ministry in Asia, NTS 5 (1958-1959) 43-45; H. Lietzmann, "Einfuhrung in die Textgeschichte der Paulusbriefe en: Kleine Schriften, II, Berlin 1958, 138-159; W. Michaelis, Teilungshypothesen bei Paulusbriefen, ThZ 14 (1958) 321-326; L. Cerfaux, Les épîtres de la captivité, en: Introduction à la Bible, II. Nouveau Testament, Tournai 1959, 475-486; J. Finegan, Light from the Ancient Past, II, Princeton 1959; B. D. Rathjen, The Three Letters of Paul to the Philippians, NTS 6 (1959-60) 167-173; B. S. Mackay, Further Thoughts on Philippians, NTS 7 (1960-61) 161-170; W. Schmithals, Zur Abfassung und älttesten Sammulung der paulinischen Briefen, ZNW 51 (1960) 225245; M. J. Suggs, Concerning the Date of Paul's Macedonian Ministry, NT 4 (1960) 6068; D. Webster, Four Bible Studies in Phil., JapChrQ 26 (1960) 3-15; D. Guthrie, NT Introduction. The pauline Epistles, London 1961; B. H. D. Hermesdorf, De ap. Paulus in lopende rekening met de gemeente te Filippi. Een vraag en veronderstelling, TsTK 1 (1961) 252-256; H. Köster, The Purpose of the Polemic of a Pauline Fragment, NTS 8 (1961-62) 317-332; W. Michaelis, Einleitung in das Neuen Testament, Bern 1961, 204-211; K. Wegenast, Das VerstÄndnis der Tradition bei Paulus und in der Deuteropaulinen, Heidelberg 1962; P. E. Davies, The Macedonian Scene of Paul's Journeys, BibArch 26 (1963) 91-106; P. Feine-J. Behm-W.G. Kümmel, Einleitung in das Neuen Testament, Heidelberg 1963, 222-230; V. P. Furnisch; The Place and Purpose od Philippians III, NTS 10 (1963) 80-88; C. O. Buchanan, Epaphroditus Sickness and the Letter to the Philippians, EvQ 36 (1964) 157-166; D. Georgi, Die Gegner des Paulus im 2 Korintherbrief. Studien zur religiösen Propaganda in der Spätantike, Neukirchen-Vluyn 1964; A. F. J. Klijn, Paul's Opponents in Philippians III, NT 7 (1964) 278-284; B. Rigaux; Paulus und seine Briefe, München 1964, 99-140; D. Georgi, Die Geschichte der Kollekte des Paulus für Jerusalemer, Hamburg-Bergstadt 1965; J. Gnilka, Die antipaulinische Mission in Philippi, BZ NF 9 (1965) 258-276; W. Schmithals, Paulus und die Gnostiker. Untersuchungen zu den Kleinen Paulusbriefen, Hamburg-Bergstadt 1965; R. H. Fuller, A Critical Introduction to the New Testament, London 1966, 34-37; A. Q. Morton-J. McLeman, Paul. A Study on the Authorship of Greek Prose, New York 1966; K.-P. Nickle, The Collection. A Study in the Strategy of Paul, London 1966, R. E. Osborne, Paul and the Wild Beasts, JBL 85 (1966) 225230; T. E. Pollard, The Integrity of Philippians, NTS 13 (1966) 57-66; P. T. Ballarini, Las Cartas de la Cautividad en general y Carta a los Filipenses, en: Introducción a la Biblia, V,2, Bilbao 1967, 23-75; H. D. Betz, Nachfolge und Nachahmung Jesus Christ in NT, Tübingen 1967, 145-153; C. J. Bahr, The Subscription in the Pauline Letters, JBL 87 (1968) 27-41; A. J. Malherbe, The Beasts at Ephesus, JBL 87 (1968) 71-80; G. OGG, The Chronology of the Life of Paul, London 1968; J. P. Berkeley, Paul and Philippians, Valley Forge (Pa.) 1969; F. F. Bruce, New Testament History, London 1969; R. Jewett, The Epistolary Thanksgiving and Integrity of Philippians, NT 12 (1970) 40-53; id. The Agitators and the Galatian Congregation, NTS 17 (1970-71) 198212; id., Conflicting Movements in the Early Church as Reflected in Philippians, NT 12 (1970) 362-390; B. Reicke, Cesarea, Rom, and The Captivity Letters; en: The Apostolic History and the Gospel (Fs F. F. Bruce), Exeter 1970, 277-285; G. Baumbach, Die Frage nach den Irrlehren in Philippi, Kairos 13 (1971) 252-266; G. Bornkamm, Der Philipperbrief als paulinische Briefsammlung, en: Geschichte und Glaube, II, München 1971, 195-205; R. Chevalier, Les voies romains, Paris 1972; J. A. Fitzmyer, Carta a los Filipenses, en: Comentario Bíblico "San Jerónimo", III. Nuevo Testamento, I, Madrid 1972, 623-638; J. J. Gunther, Paul: Messenger and Exile. A Study in the Chronology of His Life and Letters, Valley Forge (Pa.) 1972, 142 ss.; W. Schmithals, The 
False Teachers of the Epistle to the Philippians, en: Paul and the Gnostics, Nashville 1972, 65-122; D. L. Tiede, The Charismatic Figure as Miracle Worker,-Missoula (Mont.) 1972; N. Capodicasa, Gli avversari di Paolo e la "spina nella carne" (2 Cor 12,7), StPat 20 (1973) 570-589; S. Dockx, Lieu et date de l"éïtre aux Philippiens, RB 80 (1973) 230-246; J. Gunther, St. Paul's Opponents and their Background. A Study of Apocalyptic and Jewish Sectarian Teaching, Leiden 1973; L. Casson, Travel in the Ancient World, Toronto 1974; A. Conclini, Nueva traducción de la Ep. a los Filipenses, CuadT 3 (1974) 366-374; F. H. Rossi, Paolo, cittadino romano, RicBibRel 9 (1974) 23-47; E. E. Ellis, Paul and his Opponents: Trends in Research, en: Christianity, Judaism, and Other Greco-Roman Cults (Fs. M SMith), I, Leiden 1975, 264-298; B. Reese, The Apostle Paul's exercise of his Right as a Roman Citizwan as recorded in the Book of Acts, EvQ 47 (1975) 138-145; G. B. Caird, Paul's Letter from Prison, Oxford 1976; J. Ernst. From the Local Community to the Great Church, Illustrated from the Church Patterns of Philippians and Ephesians, BTB 6 (1976) 237-257; I. Fransen, Cahier de Bible: Lettre de Paul aux Philippiens, BVChr $\mathrm{n}^{\circ} 78$ (1976) 28-33; E. M. Smallwood, Jews under Roman Rule, Leiden 1976; A. E. W. Smith, Ergriffen?. Ergreife!. Die Dialektik der Gemeinschaft un ihre Folgen nach dem Philipperbrief, Stuttgart 1976; J. B. Tyson, Paul's Opponents at Philippi, PerspRelSt 3 (1976) 82-95; E. P. Sanders, Paul and Palestinian Judaism, London-Philadelphia 1977; M. Adinolfi, San Paolo e le Autorità Romane negli Atti degli Apostoli, Ant 53 (1978) 452-470; F. F. Bruce, St. Paul in Macedonia, BJRL 61 (1978-79) 337-354; J. Siat, L'empire: ses routes au premier siècle, Le Monde de la Bible 5 (1978) 16-22; A. Wikenhauser-J. Schmid, Introducción al Nuevo Testamento, Barcelona 1978, 744-760; W. J. Dalton, The Integrity of Philippians, Bi 60 (1979) 97-102; J. L. Blevins, Introduction to Philippians, RevExp 77 (1980) 311-324; . J. A. Brooks, Introduction to Philippians, SWJTh 23 (1980) 7-22; id., Exposition of Philippians, SWJTh 23 (1980) 23-36; J. D. Karavidopoulos; The Epistle to the Philippians in the modern research, DelBiblMel NS 1 (1980) 35-55; G. Lüdemann, Zum Antipaulinismus im fruhen Christentum, EvT 40 (1980) 437-455; Ph. Prokopios, The Organitation of the Philippian's Church in the Apostolic and Post-Apostolic Time: the Presbyteries of the Church at Philippi, DeltBibIMel NS 9 (1980) 56-62; F. F. Bruce, St. Paul in Macedonia: 3 The Philippian Correspondence, BJRULM 63 (1981) 260-284; D. Cook, Stephanus Le Moyne and the Dissection of Philippians, JTS 32 (1981) 138-142; M. Carrez, Pablo y la Iglesia de Filipos, en: Introducción crítica al Nuevo Testamento, I, Barcelona 1982, 573-582; R. Rusell, Pauline Letter Structure in Philippians, JEvThSoc 25 (1982) 295-306; J. Hargreaves, A Guide to Philippians, London 1983; G. Lüdemann, Paulus der Heidenapostel, II, 1. Antipaulinismus im frühen Christentum, Göttingen 1983; L. Panier, Parcours: pour lire les Actes des Apôstres. 6 ème série. Chaptîtres 16-17. De Philippes à Athènes, SemBib 35 (1984) 23-28; F. Pecriaux, Avec Paul. Pour Accompagner une lecture de sa Letre aux Filippiens, Paris 1984; D. R. Schwartz, The Accusation and the Accusers at Philippi (Actes 16,20-21), Bi 65 (1984) 357-363; S. Sonderlund, Focus on Philippians: A Review Article, Crux 20 (1984) 27-32; R. C. Swift, The Theme and Structure of Philippians, BS 141 (1984) 234-254; D. E. Garland, The Composition and Unity of Philippians. Some Neglected Literary Factors, NT 27 (1985) 141-173; M. A. Getty, Philippians: A Meditation on Community, BToday 23 (1985) 372-376; A. Moda, La lettera ai Filippesi e gli ultimi anni di Paolo Prigionero, BibOr 27 (1985) 17-30; C. J. Peifer, Three Letters in One, BToday 23 (1985) 363-368; R. Pesch, Paulus und seine Lieblingsgemeinde. Drei Briefe and die Heiligen von Philippi, Freiburg 1985; R. Schnac- 
kenburg, Paulus und seine Lieblingsgemeinde. Paulus -neu gesehen. Drei Briefe and die Heiligen von Philippi, Freiburg 1985; H. J. B. Combrink, The Role of the Reader and Other Literary Categories in Philippians, Script 20 (1987) 33-40; W. Elliger, Paulus in Griechenland. Philippi, Thessaloniki, Ethen, Korinth, Stuttgart 1987² C. Mearns, The Identity of Paul's Opponents at Philippi, NTS 33 (1987) 194-202; P. Perkins, Christology. Friedship and Status: The Rhetoric of Philippians, en: SBL 1987 Seminar Papers, Atlanta (GA) 1987, 509-520; J. D. Price, A. Computer-Aided Textual Commentary on the Book of Philippians, GraceTJ 8 (1987) 253-290; W. SChenk, Der Philipperbrief in der neueren Forschung (1945-1985), en Religión, II,25/4. Vorkonstantinisches Christentum: Leben und Umwelt Jesu: Neues Testament, Berlin-New York 1987, 3280-3313; J. P. Bercovitz, Paul at Ephesus and the Composition of Philippians, Proceedings. Eastern Great Lakes und Midwest Biblical Societies 8 (1988) 6176; D. F. Watson, A Rhetorical Analysis of Philippians and its Implications for the Unity Question, NT 30 (1988) 57-88; L. Alexander, Hellenistic Letter-Forms and Structure of Philippians, JSNT 37 (1989) 87-101; H.J.B. Comblink, Response to W. Schenk: Die Philipperbriefe des Paulus, Semeia 48 (1989) 135-146; E.A.C. Pretorius, [A. Keyto] the literature on Philippians, Neotest 23 (1989) 125-153; J.W. Voelz, Some Things New". A Response to Wolfgang Schenk: Die Philipperbriefe des Paulus, Semeia 48 (1989) 161-169; P. Vielhauer, La carta a los Filipenes, en Historia de la Literatura Cristiana Primitiva, Salamanca 1991, 173-186. 